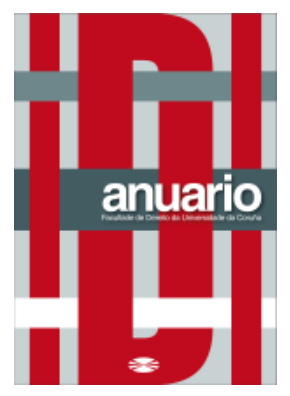

Anuario da Facultade de Dereito da Universidade da Coruña

Vol. 24 (2020), pp. 150-191

ISSNe: 2530-6324 || ISSN: 1138-039X

DOI: https://doi.org/10.17979/afdudc.2020.24.0.7467

\title{
SECRETO, TRANSPARENCIA, CONFIDENCIALIDAD Y PROTECCIÓN DE DATOS EN LA CONTRATACIÓN PÚBLICA. ESTUDIO DE LAS RESOLUCIONES DE LOS TRIBUNALES ADMINISTRATIVOS DE CONTRATACIÓN Y DEL CONSEJO DE TRANSPARENCIA Y BUEN GOBIERNO Y ÓRGANOS EQUIVALENTES
}

\author{
SECRECY, TRANSPARENCY, CONFIDENTIALITY AND DATA PROTECTION \\ IN PUBLIC PROCUREMENT. STUDY OF THE RESOLUTIONS OF THE \\ ADMINISTRATIVE PROCUREMENT TRIBUNALS AND THE TRANSPARENCY \\ AND GOOD GOVERNANCE COUNCIL AND EQUIVALENT BODIES
}

\author{
MARÍA DEL CARMEN RODRÍGUEZ MARTÍN-RETORTILLO \\ Profesora Dra. Contratada interina de Derecho Administrativo \\ Facultad de Derecho. Universidad de A Coruña \\ http://orcid.org/0000-0002-0221-7460
}

Recibido: 06/08/2020

Aceptado: 25/10/2020

\begin{abstract}
Resumen: La contratación en el ámbito del Sector Público reúne unas características peculiares, por cuanto en determinadas fases o momentos temporales tiene que quedar garantizado el secreto de las ofertas, mientras que en otras fases en virtud del principio de transparencia debe ponerse en conocimiento de los licitadores o facilitarse el acceso a determinados aspectos de las ofertas y sus valoraciones, que tan sólo encuentran su límite por una parte en el principio de confidencialidad, que no es absoluto, y en el derecho a la protección de datos personales.
\end{abstract}

Palabras clave: secreto, transparencia, confidencialidad, protección de datos, contratación pública.

Abstract: The public procurement has particular characteristics because in certain stages or temporary moments must be guaranteed the secrecy of the offers, while in others by virtue of the principle of transparency the tenderers must be informed about certain aspects of the offers and their valuation or they must be facilitated to them, that only find their limit on 
the one hand in the principle of confidentiality (which is not absolute) and on the other hand in the right to data protection.

Keywords: secrecy, transparency, confidentiality, data protection, public procurement.

Sumario: I. INTRODUCCIÓN. II. EL SECRETO DE LAS OFERTAS. 1. El secreto en la fase de presentación de las ofertas. 2. La licitación electrónica. 3. El secreto en la presentación de documentación o información de los criterios valorables mediante fórmulas. El efecto halo. 4. El secreto en el anuncio de la formalización de los contratos. 5. Los contratos declarados secretos o reservados. 6. El anonimato en los concursos de proyectos. 7. El secreto de los licitadores. III. LA TRANSPARENCIA. 1. La transparencia en la Directiva 2014/24/UE. 2. La transparencia en la normativa contractual española. 3. Aspectos en que se manifiesta la transparencia. 4. Cuando una Administración es transparente. IV. LA CONFIDENCIALIDAD. 1. La confidencialidad en el Derecho Comunitario. 2. La confidencialidad en la normativa contractual española. 3. Cuestiones a destacar por las juntas consultivas y tribunales administrativos de contratación. V. CONTRATACIÓN PÚBLICA Y PROTECCIÓN DE DATOS PERSONALES. 1. La protección de datos en la fase de preparación del contrato. 2. Obligación del adjudicatario. 3. La protección de datos en el contenido del contrato. 4. La protección de datos como condición especial de ejecución del contrato. Obligación esencial. 5. El incumplimiento de la condición especial como causa de resolución. 6. La protección de datos en la subcontratación. 7. Causa de nulidad de Derecho Administrativo. 8. La protección de datos en el registro de contratos del sector público. 9. Otras disposiciones en materia de protección de datos de carácter personal. VI. EL ACCESO A LA INFORMACIÓN DE LA CONTRATACIÓN EN LAS RESOLUCIONES DEL CONSEJO DE TRANSPARENCIA Y BUEN GOBIERNO U ÓRGANOS EQUIVALENTES DE LAS COMUNIDADES AUTÓNOMAS. VII. CONCLUSIONES. BIBLIOGRAFÍA CITADA.

\section{INTRODUCCIÓN}

La contratación en el ámbito del Sector Público reúne unas características peculiares, por cuanto en determinadas fases o momentos temporales tiene que quedar garantizado el secreto de las ofertas, mientras que en otras fases en virtud del principio de transparencia debe ponerse en conocimiento de los licitadores o facilitarse el acceso a determinados aspectos de las ofertas y sus valoraciones, que tan sólo encuentran su límite por una parte en el principio de confidencialidad, que no es absoluto, y en el derecho a la 
protección de datos personales. Por ello es esencial en la contratación pública delimitar dichos ámbitos, resolviendo las dicotomías para lograr el equilibrio y la garantía de todos los principios y derechos que aseguren en cada fase o trámite de la contratación el secreto, la transparencia versus confidencialidad y la protección de datos, y sus límites. A lo largo de este trabajo vamos a analizar estos aspectos.

\section{EL SECRETO DE LAS OFERTAS}

El secreto de presentación de las ofertas garantiza la igualdad de todos los licitadores. Lograr que las ofertas se presenten en sobre cerrado ha representado un avance extraordinario en la contratación pública. En la primera mitad del siglo XIX no se aseguraba el secreto en la presentación de las ofertas y daba lugar a situaciones que no garantizaban la igualdad de los licitadores. El Decreto de 27 de febrero de $1852^{1}$ representó un hito fundamental para la presentación de ofertas en sobre cerrado, y ya la exposición de motivos indicaba las disfunciones de la no utilización de sobres cerrados ${ }^{2}$ y resaltaba la importancia del secreto de las ofertas ${ }^{3}$. En el art. 2 ya se especificaba que la proposición debería presentarse por escrito y en pliegos cerrados.

\section{El secreto en la fase de presentación de las ofertas}

A comienzos del siglo $\mathrm{XX}$, ya se consolida el secreto de las ofertas, que se va a mantener en la normativa posterior. Así, el art. 48 de la Ley de Administración y Contabilidad de la Hacienda Pública de $1911^{4}$, el art. 2 del Reglamento de 2 de julio de 1924, para la contratación de las obras y servicios a cargo de las entidades municipales ${ }^{5}$ y el art. 18 del Reglamento de Contratación de las Corporaciones Locales $^{6}$ regularon igualmente el secreto de las ofertas. El Decreto 3354/1967, de 28 de diciembre, por el que se aprueba el Reglamento General de Contratación para la aplicación de la Ley de

\footnotetext{
${ }^{1}$ Gaceta de Madrid n ${ }^{\circ}$ 6460, de 29 de febrero de 1852.

2 “...a dos graves inconvenientes estaban sujetas las subastas públicas. Consistía el primero en la confabulación de los licitadores o en la introducción de un tercero en la licitación con el fin de obligar a los demás a concederle una prima para evitar sus pujas; y en el segundo en el acaloramiento de los mismos, que solían llevarlos a veces a hacer proposiciones tan onerosas que no les era posible cumplir después. El resultado de esto era con frecuencia que, creyendo la Administración haber obtenido contratos ventajosos, veía al fin burladas sus esperanzas con pérdida de tiempo y de dinero”.

3 "De este modo, ignorando los licitadores la extensión de las propuestas de sus concesiones, calcularán tranquilamente lo que pueden ofrecer, y ofrecerán cuanto puedan por el temor de que otros hagan lo mismo; y por medio de este regulador la Administración celebrará sus contratos dentro de los límites que la equidad y la justicia prescriben".

4 “... el modelo de proposiciones que habrán de presentarse por escrito en sobre cerrado...”; art. 50 de la Ley de 20 de diciembre de 1952 por la que se sustituye la redacción del capítulo V de la Ley de Administración y Contabilidad de la Hacienda Pública, de 1 de julio de 1911, relativo a los contratos para la ejecución de obras y servicios públicos.

${ }^{5}$ Art. 2: “...Las licitaciones se verificarán siempre por medio de pliegos cerrados, sujetándose las proposiciones que se presenten al modelo prescrito para el caso por la Corporación Contratante”.

${ }^{6}$ Art. 18 RCCL: "En las subastas, concursos-subastas y concursos deberán observarse, con arreglo al presente Reglamento, estos fundamentales principios: a) publicidad de la licitación. b) secreto de las proposiciones”.
} 
Contratos del Estado, texto articulado aprobado por Decreto 923/1965, de 8 de abril, lo regulaba en los arts. 100 y $103^{7}$. Lo ha regulado igualmente el art. 80 de la Ley 13/95 ${ }^{8}$, el art. 79 del TRLCAP ${ }^{9}$, el art. 80.1 y 83 del RGCAP, el art .129.2 de la Ley 30/2007 ${ }^{10}$ y el art. 145 del TRLCSP ${ }^{11}$. El art. 139.2 de la Ley 9/2017 (LCSP), declara que "Las proposiciones serán secretas y se arbitrarán los medios que garanticen tal carácter hasta el momento de apertura de las proposiciones, sin perjuicio de lo dispuesto en los artículos 143, 175 y 179 en cuanto a la información que debe facilitarse a los participantes en una subasta electrónica, en un diálogo competitivo, o en un procedimiento de asociación para la innovación”. En este sentido son numerosas las Resoluciones que excluyen ofertas por presentarse abiertos los sobres, cuando la presentación no era electrónica ${ }^{12}$.

7 Art. 100: “Las proposiciones u ofertas contractuales habrán de ser entregadas a mano en las dependencias u oficinas expresadas en el anuncio dentro del plazo de admisión señalado en el mismo. No se admitirán las enviadas por correo o cualquier otro procedimiento diferente del señalado salvo que el anuncio de la licitación lo autorice, respetándose siempre el secreto de la oferta”. Art. 103: "En caso de discrepancia entre las proposiciones que obren en poder de la Mesa y las que como presentadas se deduzcan de las certificaciones de que dispone la misma, o que se presenten dudas sobre las condiciones de secreto en que han debido ser custodiadas, se suspenderá el acto y se realizarán urgentemente las investigaciones oportunas sobre lo sucedido, volviéndose a anunciar nuevamente una vez que todo haya quedado aclarado en la debida forma".

8 Art. 80 LCAP. Proposiciones de los interesados: “1. Las proposiciones serán secretas y se arbitrarán los medios que garanticen tal carácter hasta el momento de la licitación pública (...)”.

${ }^{9}$ Art. 79 TRLCAP: “1. Las proposiciones serán secretas y se arbitrarán los medios que garanticen tal carácter hasta el momento de la licitación pública (...)”.

10 Art. 129. Proposiciones de los interesados: “2. Las proposiciones serán secretas y se arbitrarán los medios que garanticen tal carácter hasta el momento de la licitación pública, sin perjuicio de lo dispuesto en los artículos 132 y 166 en cuanto a la información que debe facilitarse a los participantes en una subasta electrónica o en un diálogo competitivo”.

${ }^{11}$ Art. 145.2 TRLCSP: "Las proposiciones serán secretas y se arbitrarán los medios que garanticen tal carácter hasta el momento de la licitación pública, sin perjuicio de lo dispuesto en los artículos 148 y 182 en cuanto a la información que debe facilitarse a los participantes en una subasta electrónica o en un diálogo competitivo".

12 A nivel comunitario citamos la Sentencia del Tribunal General (Sala Sexta) de 30 de abril de 2014, que ratifica la exclusión de una oferta, por el siguiente motivo: "El sobre postal exterior de la empresa de mensajería estaba cerrado pero no sellado. Los sobres incluidos dentro, que eran el único embalaje presentado por el licitador, estaban en gran parte rotos, hasta el punto de estar completamente abiertos. La comisión consideró que no se garantizaba la confidencialidad y, en consecuencia, excluyó la oferta”. La Resolución n³8/2017 del TACRC señala que "entroncando con esta perspectiva de salvaguardia de la integridad del procedimiento de contratación, cabe añadir, en fin, una vertiente adicional del secreto de las proposiciones, a saber: la defensa de los derechos e intereses del resto de los licitadores, para los cuales aquél es garantía de que la Administración no dispensa un trato de favor a ninguno de los concurrentes. Esta dimensión, a la que aludimos en nuestras Resoluciones 205/2011 y 300/2012, subyace en la regulación que se contiene en el artículo 83 RGLCAP del acto público de apertura de las proposiciones, que prevé que se dé ocasión a los interesados "para que puedan comprobar que los sobres que contienen las ofertas se encuentran en la mesa y en idénticas condiciones en que fueron entregados” (apartado 2) y que, cuando se susciten "dudas sobre las condiciones de secreto en que han debido ser custodiadas", se suspenda el acto y se realicen "urgentemente las investigaciones oportunas sobre lo sucedido" no reanudándose hasta que "todo haya quedado aclarado en la debida forma” (apartado 3). Es obvio que tales cautelas sólo tienen sentido si se estima que el mantenimiento del secreto de las proposiciones -al que está destinada la exigencia de presentar la documentación en sobres cerrados- también tutela la posición de los competidores que cumplen con la carga de presentar la oferta en sobre cerrado, interesados como están en evitar cualquier trato de favor que beneficie a uno de los licitadores”. 


\section{La licitación electrónica}

La Ley 9/2017 (LCSP), en cumplimiento de la Directiva 2014/24/UE, ha supuesto la obligatoriedad de la presentación electrónica de las ofertas, con las únicas excepciones de la Disposición adicional $15^{\mathrm{a}}$. La presentación electrónica garantiza el secreto de la oferta, tal y como establece la Disposición adicional decimoséptima de la $\operatorname{LCSP}^{13}$ al indicar que con las herramientas y dispositivos pueda garantizarse razonablemente que nadie tenga acceso a los datos y documentos transmitidos a tenor de los presentes requisitos antes de que finalicen los plazos especificados. El secreto de la oferta es esencial por tanto en la contratación pública, de tal modo que no se pueda acceder al contenido de la oferta ${ }^{14}$, e incluso debería garantizarse que tampoco se pueda acceder al nombre y número de licitadores hasta que finalice el plazo de presentación, y se proceda a su apertura por la correspondiente Mesa de Contratación u órgano autorizado de la Administración ${ }^{15}$. El secreto de presentación de ofertas garantiza la igualdad y la concurrencia. Como señala VILLAR PALASÍ, "la regla del secreto obedece a la preocupación por salvaguardar los intereses económicos de la Administración, y es también salvaguarda del derecho a la igualdad de oportunidades de todos los licitadores frente a los manejos que los funcionarios públicos pudieran intentar en favor de uno de ellos” ${ }^{16}$.

\section{El secreto en la presentación de documentación o información de los criterios valorables mediante fórmulas. El efecto halo}

Hay otro momento importante en que debe mantenerse el secreto de la oferta, es en el supuesto de que se valoren criterios mediante juicios de valor y criterios mediante fórmulas. Aquí también se ha establecido, aunque desde tiempos más recientes, que las ofertas incluyan en un sobre o archivo electrónico la documentación relativa a juicios de valor y en otro sobre o archivo electrónico las ofertas que son objeto de valoración mediante fórmulas. En estos casos primero se abrirán los sobres de juicio de valor y después de valorarse por el correspondiente comité de expertos o servicios técnicos se procederá a la apertura del sobre que contiene la oferta basada en fórmulas ${ }^{17}$. Este secreto temporal es fundamental, pues se pueden dar 2 hipótesis:

13 Requisitos específicos relativos a las herramientas y los dispositivos de recepción electrónica de documentos.

${ }^{14}$ Art. 129.2 Ley 30/2007, ya citado. Igualmente, en el art. 145.2 TRLCSP, ya citado.

15 Cuando tiene que intervenir la mesa de contratación se regula en los arts. 325 y 326 LCSP (mesa diálogo competitivo) y Disp. Adicional $2^{\mathrm{a}}$ LCSP.

${ }^{16}$ VILLAR PALASÍ, J.L., Lecciones sobre contratación administrativa, Facultad de Derecho, Sección de publicaciones, 1969.

${ }^{17}$ Esta exigencia se regula por primera vez en el art. 130.2 de la Ley de Contratos de Sector Público de 2007: "La evaluación de las ofertas conforme a los criterios cuantificables mediante la mera aplicación de fórmulas se realizará tras efectuar previamente la de aquellos otros criterios en que no concurra esta circunstancia, dejándose constancia documental de ello. Las normas de desarrollo de esta Ley determinarán los supuestos y condiciones en que deba hacerse pública tal evaluación previa, así como la forma en que deberán presentarse las proposiciones para hacer posible esta valoración separada”. Siguen esta línea el TRLCSP, art. 150.2: "La evaluación de las ofertas conforme a los criterios cuantificables mediante la mera aplicación de fórmulas se realizará tras efectuar previamente la de aquellos otros criterios en que no concurra esta circunstancia, dejándose constancia documental de ello. Las normas de desarrollo de esta Ley determinarán los supuestos y condiciones en que deba hacerse pública tal evaluación previa, así como la 
a) si es la Administración la que lo desvela, por ejemplo, abriendo antes o simultáneamente el sobre de fórmulas que el de juicios de valor, la licitación debería ser anulada,

b) si el licitador introduce información de criterios basados en fórmulas en el sobre de juicios de valor su oferta deberá ser excluida, y en esta línea se han pronunciado numerosas resoluciones de los Tribunales de Contratación ${ }^{18}$.

Esta información puede haberse incluido en el sobre o archivo electrónico de documentación general y también sería causa de exclusión ${ }^{19}$. Pues como pone de manifiesto la Resolución $\mathrm{n}^{0740 / 2020}$ del TACRC “en los procedimientos en los que se establezcan criterios de valoración objetiva o mediante la aplicación de fórmulas matemáticas, deberán cuantificarse con posterioridad a la valoración de los criterios sometidos a juicio de valor, que, además, deberán ser hechos públicos con antelación. Y ello viene motivado por la necesidad de garantizar que los criterios sometidos a juicio de valor no puedan verse condicionados por la previa valoración de los elementos objetivos. En tal caso se correría el riesgo de permitir al órgano de contratación otorgar una mayor o menor puntuación a estos criterios subjetivos para acomodar la puntuación total a la luz de la puntuación obtenida en la valoración de los criterios sujetos a fórmula matemática”. Este requisito está vinculado al principio de igualdad de trato ${ }^{20}$. El Consejo de Estado también

forma en que deberán presentarse las proposiciones para hacer posible esta valoración separada”. Y la Ley 9/2017 en su art. 146: "En todo caso, la evaluación de las ofertas conforme a los criterios cuantificables mediante la mera aplicación de fórmulas se realizará tras efectuar previamente la de aquellos otros criterios en que no concurra esta circunstancia, dejándose constancia documental de ello”.

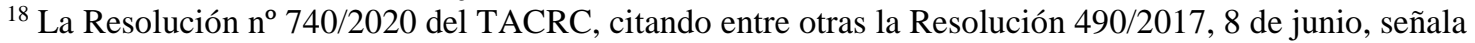
que "cuando la apertura de un sobre que contiene la oferta objeto de ponderación con criterios de valor, contiene datos de la parte de la oferta que debe valorarse conforme a criterios objetivos, la oferta debe excluirse. Este principio general, que, como recuerda la empresa recurrente, no admite excepciones, sí que exige una cuidadosa constatación de que tal efecto de "contaminación" de unas valoraciones con otras, que es lo que se pretende evitar, se ha producido realmente y es susceptible de haber condicionado la primera de las valoraciones. De todo ello, se hacen eco las resoluciones 771/2016, de 30 de septiembre, 67/2012, 62/2013, 688/2014, 890/2014, 661/2015 y 8/20 y la resolución citada por la empresa recurrente 749/2019, que la excluyó de otro proceso de selección. "Ello es así porque, con tal proceder, se infringe el secreto de las proposiciones hasta la licitación pública (cfr.: artículos 145.2 y 160 TRLCSP) y hace imposible la aplicación de la regla fundamental en nuestro Ordenamiento (cfr.: artículos 150.2 TRLCSP y 26 y 30.2 del Real Decreto 817/2009, de 8 de mayo, por el que se desarrolla parcialmente la Ley 30/2007, de 30 de octubre, de Contratos del Sector Público; Resolución 110/2014, Sentencia de la Audiencia Nacional de 6 de noviembre de 2012155/2014, de 20 de febrero, 761/2014, de 14 de octubre, 193/2015, de 26 de febrero, 673/2015, de 17 de julio, y 225/2016, de 1 de abril), y finalmente la sentencia del Tribunal de Justicia de la Unión Europea, de 30 de abril de 2014, Asunto T-637/2011, afirmó que se puede “(...) considerar garantizada la confidencialidad de las ofertas [por]que la comisión de apertura de las ofertas [se] halle en dos sobres sellados intactos. Según se afirma en la primera de las resoluciones citadas "esta norma contribuye de este modo a la seguridad jurídica, eliminando cualquier riesgo de apreciación arbitraria en la apertura de las ofertas”.

19 “... cabe concluir que cuando la apertura del sobre conteniendo la documentación general implique el conocimiento, total o parcial, de la oferta del licitador por encontrarse incluido en él alguno de los datos que debieran figurar en el sobre de la proposición, debe producirse, en todo caso, la exclusión del licitador afectado respecto del procedimiento de adjudicación de que se trate (Resolución núm. 3/2019, de 10 de enero, del Tribunal Administrativo de Contratos Públicos de la Comunidad Autónoma de Canarias)”.

${ }^{20}$ El TACRC ha declarado en múltiples resoluciones (por ejemplo, resoluciones 628/2013, 47/2012 y 173/2012), que "el principio de igualdad de trato implica que todos los licitadores deben hallarse en pie de 
se ha pronunciado sobre esta cuestión. Así, en su Dictamen 670/2013, de 11 de julio de 2013 ha señalado que "del sucinto examen realizado cabe colegir dos ideas: primera, la importancia del secreto de las proposiciones, no como objetivo en sí mismo, sino como garantía del conocimiento sucesivo de la documentación relativa a los criterios cuya cuantificación dependa de un juicio de valor y de la referida a los parámetros evaluables de forma automática, de modo que se favorezca la objetividad de la valoración y con ello la igualdad de trato de los licitadores; $\mathrm{y}$, segunda, la necesidad de ponderar las circunstancias concurrentes a la hora de excluir ofertas que incumplan o cumplan defectuosamente los requisitos formales de presentación de la documentación (bien porque ésta obre en sobres abiertos, bien porque se incluya erróneamente información propia de un sobre en otro distinto), en el bien entendido de que la exclusión está justificada cuando el incumplimiento o cumplimiento defectuoso de tales requisitos, incluido el secreto de las proposiciones hasta la licitación pública, menoscabe la objetividad de la valoración y el tratamiento igualitario de los licitadores como valores que se trata de preservar mediante dicho secreto, pero no lo está cuando no se haya visto afectado sustantivamente el principio de igualdad de trato" ${ }^{21}$.

En igual sentido la Resolución del Tribunal Administrativo de Recursos Contractuales de la Junta de Andalucía ${ }^{22}$ ha incidido en la importancia de mantener el secreto de las proposiciones, mediante la separación y valoración de los sobres en momentos procedimentales diferentes para hacer efectivo el principio de igualdad. La Resolución n¹304/2019 insiste en esta cuestión al indicar que "tal y como este Tribunal ha señalado en su Resolución 67/2012 de 14 de marzo, cualquier acto que implique el conocimiento del contenido de las proposiciones (características de la oferta) antes de que se celebre el acto público de apertura, rompe el secreto de las proposiciones y, por tanto, es contrario tanto a lo previsto en el artículo 160 TRLCSP, que dispone, “en todo caso, la apertura de la oferta económica se realizará en acto público, salvo cuando se prevea que en la licitación puedan emplearse medios electrónicos”, como a lo señalado en el artículo 145 TRLCSP de conformidad con el cual "las proposiciones serán secretas y se arbitrarán los medios que garanticen tal carácter hasta el momento de la licitación pública”.

Siendo cierto que el supuesto más grave posible de equivocación se refiere a aquel en el que se anticipa información económica o evaluable automáticamente porque puede llegar a servir para configurar de un modo arbitrario el informe de valoración en atención a la información que se obtiene; no deja de ser cierto también en el presente caso que el error cometido rompe el secreto de las proposiciones, y aunque sea cierto a priori que la mesa de

igualdad tanto en el momento de presentar sus ofertas como al ser valoradas éstas por la entidad adjudicadora (sentencia del TJUE de 25 de abril de 1996, Comisión/Bélgica)", y que "a esta exigencia obedece que los artículos 145 y 160.1 del TRLCSP establezcan que las proposiciones de los interesados conteniendo las características técnicas y económicas deben mantenerse secretas hasta el momento en que deban ser abiertas”.

21 "La necesidad de preservar la imparcialidad y objetividad en el proceso de adjudicación exige la separación necesaria entre la apertura de la documentación administrativa y la toma de conocimiento de la proposición económica, e impone el carácter secreto de todas las proposiciones, cuyo incumplimiento ha de conllevar la nulidad del procedimiento (STS de 2 de julio de 2004, rec. 3885/2000)”.

22 "El mandato legal de separación y valoración en momentos procedimentales diferentes de una y otra documentación, lejos de ser tildado de formalista, responde a la necesidad de preservar la objetividad e imparcialidad en la valoración de las proposiciones, en aras de hacer efectivo el principio de igualdad de trato consagrado en el artículo 1.1 de la LCSP, piedra angular sobre la que se vertebra cualquier licitación pública” (Resolución 187/2020 de 1 de junio de 2020). 
contratación solamente ha obtenido una información de manera adelantada que habría de haber valorado igualmente de haberla recibido con posterioridad, y no goza de otros elementos de contexto que puedan hacer pensar que las circunstancias descritas pudieran mover a beneficiar (o también perjudicar), es razonable pensar que pueden llegar a producirse otras circunstancias o decisiones en el procedimiento en las que podría afectar ese conocimiento anticipado de la oferta de la recurrente, existiendo una contaminación en el conocimiento de la mesa”.

La Resolución nº1275/2019 indica cómo el conocimiento previo puede comprometer la objetividad en la evaluación ${ }^{23}$. Finalmente, cabe traer aquí la Resolución n $538 / 2019$ del TACRC de 16 de mayo de $2019^{24}$.

También es relevante la Resolución n066/2020, de 22 de mayo, del Órgano Administrativo de Recursos Contractuales de la Comunidad Autónoma de Euskadi, que pone de manifiesto, (citando la Resolución 19/2020) que la finalidad de la evaluación separada y sucesiva de ambos tipos de criterio es evitar que el conocimiento de los aspectos de la oferta evaluables mediante fórmulas condicione los juicios de valor que necesariamente habrán de emitirse para aplicar los criterios de adjudicación no sujetos a la aplicación de fórmulas ${ }^{25}$.

El sistema anula también el denominado "efecto halo" en la atribución de puntuaciones al separar radicalmente la valoración de cada tipo de criterio, impidiendo, por ejemplo, que quien efectúa el informe técnico tienda a sobrevalorar la calidad de una oferta que objetivamente no merece una alta puntuación en este apartado porque sabe que también es la más barata. La sanción al licitador que infringe materialmente esta regla de presentación, de modo que posibilita el conocimiento prematuro de un aspecto evaluable mediante fórmula en perjuicio de una aplicación objetiva y no discriminatoria de los

23 “En este sentido, la citada Resolución 727/2019 concluye que "en definitiva, el órgano encargado de la evaluación de criterios dependientes de un juicio de valor sabía ya, antes de la apertura del sobre destinado a la información evaluable mediante fórmulas, que el licitador iba a recibir 7 puntos por este concepto. Por ello, y a diferencia de lo sucedido en la Resolución última citada, ha resultado comprometida la objetividad del órgano de contratación en la evaluación de los criterios de adjudicación. Y ello rompe el secreto de la proposición y la garantía de separación entre una y otra información preservada por nuestra norma para asegurar la objetividad en la valoración de los criterios dependientes de un juicio de valor y, en definitiva, la igualdad entre licitadores, siendo procedente la exclusión”, lo que resulta plenamente aplicable al presente supuesto".

${ }^{24}$ Conforme a la cual: “... el conocimiento anticipado por el órgano de contratación de las ofertas evaluables automáticamente o mediante fórmula puede condicionar el juicio de valor que, en el caso de existir, siempre ha de tener carácter previo. Así lo ha señalado la Sentencia de la Audiencia Nacional, Sección Primera, de 18 de diciembre de 2013, recurso de apelación 23/2013, Fundamento de Derecho Sexto. Este mismo principio ha sido objeto de una aplicación reiterada en la doctrina de este Tribunal, proyectándose en este caso sobre la necesidad de excluir a los licitadores que incluyan documentación sobre la proposición económica o evaluable mediante fórmula en el sobre correspondiente a la documentación evaluable por juicio de valor. Así, y sobre la base del principio de igualdad de trato, podemos citar la Resolución 286/2019 de 25 de marzo, recurso nº138/2019 o la Resolución 1137/2017, de 1 de diciembre”.

${ }^{25}$ Es decir, se busca la objetividad en el juicio de valor, que podría verse comprometida si quien tiene que configurarlo conoce total o parcialmente el resultado de la evaluación de los criterios automáticos, pues en ese caso podría darse una valoración que, consciente o inconscientemente, compensara las puntuaciones resultantes de dicha evaluación en favor o perjuicio de alguna empresa. 
criterios de adjudicación, es la exclusión de la oferta, sin que quepa que el órgano de contratación gradúe dicha consecuencia en atención a la buena fe del operador y sin que sea necesario probar la existencia de un daño efectivo a dicha objetividad (ver, en este sentido la Resolución 43/2020 del OARC/KEAO).

En igual sentido se pronuncia la Resolución n³/2019, de 10 de enero, del Tribunal Administrativo de Contratos Públicos de la Comunidad Autónoma de Canarias ${ }^{26}$.

\section{El secreto en el anuncio de la formalización de los contratos}

La ley recoge determinadas circunstancias en las que determinados aspectos del expediente no se pueden publicar ${ }^{27}$.

\section{Los contratos declarados secretos o reservados}

Este tipo de $\operatorname{contratos}^{28}$, por sus peculiaridades, están sujetos a unas restricciones que abarcan desde la excepción a la licitación ${ }^{29}$, su no consideración como sujetos a

26 “La citada normativa persigue por tanto una doble garantía, por un lado, asegurar que la información contenida en las proposiciones no ha podido ser manipulada ni alterada en el período de tiempo transcurrido entre su presentación por el licitador y su apertura en acto público y por otro, que los asistentes al acto público de apertura de las ofertas puedan verificar que efectivamente se ha cumplido la garantía antes citada. El secreto que afecta a las proposiciones de los licitadores, además de poder ser verificable cuando tenga lugar el acto público de apertura de las ofertas, alcanza no sólo a otros licitadores en el procedimiento sino incluso a los propios gestores del expediente de contratación, incluidos los miembros de las Mesas de contratación a quien corresponde valorar las ofertas, y cuyo conocimiento no podrá ser anterior al momento de su apertura en el correspondiente acto público".

${ }^{27}$ Art. 154.7 LCSP: "Podrán no publicarse determinados datos relativos a la celebración del contrato cuando se considere, justificándose debidamente en el expediente, que la divulgación de esa información puede obstaculizar la aplicación de una norma, resultar contraria al interés público o perjudicar intereses comerciales legítimos de empresas públicas o privadas o la competencia leal entre ellas, o cuando se trate de contratos declarados secretos o reservados o cuya ejecución deba ir acompañada de medidas de seguridad especiales conforme a la legislación vigente, o cuando lo exija la protección de los intereses esenciales de la seguridad del Estado y así se haya declarado de conformidad con lo previsto en la letra c) del apartado 2 del artículo 19. En todo caso, previa la decisión de no publicar unos determinados datos relativos a la celebración del contrato, los órganos de contratación deberán solicitar la emisión de informe por el Consejo de Transparencia y Buen Gobierno a que se refiere la Ley 19/2013, de 9 de diciembre, de transparencia, acceso a la información pública y buen gobierno, en el que se aprecie si el derecho de acceso a la información pública prevalece o no frente a los bienes que se pretenden salvaguardar con su no publicación, que será evacuado en un plazo máximo de diez días. No obstante lo anterior, no se requerirá dicho informe por el Consejo de Transparencia y Buen Gobierno en caso de que con anterioridad se hubiese efectuado por el órgano de contratación consulta sobre una materia idéntica o análoga, sin perjuicio de la justificación debida de su exclusión en el expediente en los términos establecidos en este apartado”.

28 Vid. BASSOLS COMA, M., "La confidencialidad en la resolución del recurso especial en materia de contratación en el sector de la defensa y la seguridad pública y el Tribunal Administrativo Central de Recursos Contractuales”, Documentación Administrativa, N²88, 2010, págs. 99-127.

${ }^{29}$ Art. 168. Supuestos de aplicación del procedimiento negociado sin publicidad: “(...) $3 .{ }^{\circ}$ Cuando el contrato haya sido declarado secreto o reservado, o cuando su ejecución deba ir acompañada de medidas de seguridad especiales conforme a la legislación vigente, o cuando lo exija la protección de los intereses esenciales de la seguridad del Estado y así se haya declarado de conformidad con lo previsto en la letra c) del apartado 2 del artículo 19 (...)”. 
regulación armonizada ${ }^{30}$, hasta la documentación del contrato $^{31}$, la necesidad de autorización previa de la subcontratación ${ }^{32}$ y las limitaciones a la celebración de encuestas $^{33}$. A los contratos declarados secretos o reservados de conformidad con la Ley 9/1968, de 5 de abril, sobre secretos oficiales, se les aplicará dicha norma y, en defecto de lo establecido en la misma, se regirán por lo dispuesto en la presente Ley ${ }^{34}$. Esta norma precisa de una modificación para adaptarse a la situación actual, existiendo ya iniciativas parlamentarias al respecto.

\section{El anonimato en los concursos de proyectos}

Los concursos con intervención de jurado podemos decir que son un instrumento extraordinario para seleccionar determinados proyectos de arquitectura, ingeniería, etc., pues a través de la presentación anónima el jurado no se va a ver condicionado por los nombres del autor, tan solo verificará la calidad del proyecto sin otros condicionantes. Vienen regulados en los arts. 183 a 187 de la LCSP y se caracterizan por la presentación anónima de los proyectos (art. 187.4), que tiene que mantenerse hasta que el jurado emita su dictamen o decisión (art. 187.6). Es decir, se mantienen en secreto los datos del licitador hasta la fase final. La ruptura o no garantía de este anonimato ha dado lugar a diversas resoluciones de los Tribunales de contratación ${ }^{35}$.

\footnotetext{
${ }^{30}$ Art. 19.2.c) LCSP:

"No obstante lo señalado en el apartado anterior, no se consideran sujetos a regulación armonizada, cualquiera que sea su valor estimado, los contratos siguientes:

c) Los declarados secretos o reservados, o aquellos cuya ejecución deba ir acompañada de medidas de seguridad especiales conforme a la legislación vigente, o en los que lo exija la protección de intereses esenciales para la seguridad del Estado, cuando la protección de los intereses esenciales de que se trate no pueda garantizarse mediante la aplicación de las normas que rigen los contratos sujetos a regulación armonizada en esta Ley.

La declaración de que concurre la circunstancia relativa a la protección de intereses esenciales para la seguridad del Estado deberá hacerse de forma expresa en cada caso por el titular del Departamento ministerial del que dependa el órgano de contratación en el ámbito de la Administración General del Estado, sus Organismos Autónomos, Entidades Gestoras y Servicios Comunes de la Seguridad Social y demás entidades públicas integrantes del sector público estatal, por el órgano competente de las Comunidades Autónomas, de las Ciudades Autónomas de Ceuta y Melilla, o por el órgano al que esté atribuida la competencia para celebrar el correspondiente contrato en las Entidades locales. La competencia para efectuar esta declaración no será susceptible de delegación, salvo que una ley expresamente lo autorice”.

${ }^{31}$ Art. 154.7 LCSP, ya citado.

${ }^{32}$ Art. 215. Subcontratación: "2. La celebración de los subcontratos estará sometida al cumplimiento de los siguientes requisitos: (...) d) En los contratos de carácter secreto o reservado, o en aquellos cuya ejecución deba ir acompañada de medidas de seguridad especiales de acuerdo con disposiciones legales o reglamentarias o cuando lo exija la protección de los intereses esenciales de la seguridad del Estado, la subcontratación requerirá siempre autorización expresa del órgano de contratación”.

${ }^{33}$ Art. 332.7 LCSP: “(...) b) Podrá realizar encuestas e investigaciones, para lo que tendrá acceso a los órganos y servicios de contratación, que deberán facilitar los datos, documentos o antecedentes o cualquier información que aquella les reclame, salvo que tengan carácter secreto o reservado”.

${ }^{34}$ Disposición Adicional trigésima séptima LCSP.

${ }^{35}$ La Resolución 181/2018, de 18 de diciembre de 2018, de la Titular del Órgano Administrativo de Recursos Contractuales de la Comunidad Autónoma de Euskadi estima un recurso por no ser conforme a derecho la cláusula al no exigir la presentación de las propuestas completas de forma anónima.

De igual modo, la Resolución no 219/2018 del Tribunal Administrativo de Contratación Pública de la Comunidad de Madrid de 18 de julio de 2018, estima el recurso porque no quedó garantizado el anonimato ("En consecuencia, la necesaria independencia a la que nos referíamos quedó comprometida por esos dos
} 


\section{El secreto de los licitadores}

El secreto abarca también la obligación de no comunicar entre licitadores las ofertas durante el plazo de convocatoria y presentación de ofertas y el respeto a la normativa de la competencia ${ }^{36}$, en especial la no adopción de prácticas restrictivas de la competencia $^{37}$, e incluso con consecuencias penales derivadas de las maquinaciones para alterar el precio de los concursos y subastas ${ }^{38}$. Como acabamos de exponer, el secreto es esencial en estas fases, pero tiene también un límite temporal, puesto que, una vez finalizado el plazo de presentación de ofertas, con la apertura de sobres, por la Mesa de contratación o en su caso por el órgano de la Administración, se levanta dicho secreto. De igual modo cuando se ha evaluado el sobre que contiene la documentación relativa a juicios de valor se levanta dicho secreto una vez abierto el sobre relativo a fórmulas, aunque como veremos más adelante su conocimiento general puede verse limitado por la declaración de determinados documentos como confidenciales. La licitación electrónica ha supuesto un refuerzo para el secreto de las ofertas, dado que requiere una triple operación:

factores, la ruptura del anonimato y la actuación previa del propio jurado, que no le permitía, en ningún caso, admitir alegaciones que supusieran modificar la clasificación realizada").

${ }^{36}$ Cabe mencionar la Sentencia del Tribunal Supremo, de la Sección 3 de la Sala de lo Contencioso (Roj: STS 438/2016) de 15 de febrero de 2016 ( $\mathrm{N}^{\circ}$ de Recurso: 3853/2013):

"[...] La conducta por la que se sanciona a las ahora recurrentes, que la CNC entiende tipificada en el art. 1 de la Ley 15/2007 es la participación en la organización de un mecanismo para acordar ofertas en las licitaciones públicas de conservación, mejora, renovación y rehabilitación de firmes y plataformas. Este mecanismo de coordinación operaba en licitaciones organizadas en base al procedimiento restringido; entre las empresas invitadas a presentar oferta económica se producían contactos y reuniones, que tenían por objeto analizar, para una o varias licitaciones, las ofertas que las empresas invitadas a cada una de ellas tenían previsto presentar en condiciones competitivas. ...

A partir de estos indicios, esta Sala considera que se han probado de forma suficiente los hechos base: se celebran contactos y reuniones, participan empresas invitadas a participar en determinado tipo de licitaciones, se comunican sus ofertas, se detallan las bajas a ofertar. Y el resultado es que la baja más alta siempre es mucho más reducida que la inicialmente prevista por el licitador con la oferta más ventajosa para la Administración. Y en alguno de los concursos públicos, se ha acreditado que se calcula porcentualmente, y en relación con la baja de cada uno, un importe en euros que es una parte de la diferencia que resulta, a favor del adjudicatario y en contra de la Administración que convoca y adjudica el concurso de comparar la cifra con la baja más alta inicialmente prevista y la cifra con la baja más pequeña finalmente ofertada. Ha tenido lugar la demostración del enlace preciso y directo entre el hecho base acreditado y la consecuencia obtenida por la CNC, y que este razonamiento no es arbitrario ni absurdo, sino que es coherente y razonable”.

${ }^{37}$ Ley 15/2007, de 3 de julio, de Defensa de la Competencia. Vid. Sentencia del TS (Roj: STS 2810/2015) de 22 de junio de 2015, entre otras.

38 Art. 262 CP. Alteración de precios de concursos y subastas: "1. Los que solicitaren dádivas o promesas para no tomar parte en un concurso o subasta pública; los que intentaren alejar de ella a los postores por medio de amenazas, dádivas, promesas o cualquier otro artificio; los que se concertaren entre sí con el fin de alterar el precio del remate, o los que fraudulentamente quebraren o abandonaren la subasta habiendo obtenido la adjudicación, serán castigados con la pena de prisión de uno a tres años y multa de 12 a 24 meses, así como inhabilitación especial para licitar en subastas judiciales entre tres y cinco años. Si se tratare de un concurso o subasta convocados por las Administraciones o entes públicos, se impondrá además al agente y a la persona o empresa por él representada la pena de inhabilitación especial que comprenderá, en todo caso, el derecho a contratar con las Administraciones públicas por un período de tres a cinco años.

2. El juez o tribunal podrá imponer alguna o algunas de las consecuencias previstas en el artículo 129 si el culpable perteneciere a alguna sociedad, organización o asociación, incluso de carácter transitorio, que se dedicare a la realización de tales actividades”. 
1.- descifrado,

2.- apertura de documentación, y

3.- descarga de documentación.

Si bien como propuesta de mejora se sugiere que la relación de ofertas presentadas no llegue a la Administración o ente contratante hasta que finalice el plazo de presentación.

\section{LA TRANSPARENCIA}

La transparencia es uno de los grandes principios construidos por el Derecho Comunitario, tanto en las Directivas como en la jurisprudencia del Tribunal de Justicia de la Unión Europea, y como analizaremos en este apartado, ha impregnado la normativa contractual española, entre otras. Se ha definido la transparencia como la “Obligación de las administraciones públicas y otras entidades públicas y privadas, como los partidos políticos o las entidades subvencionadas, de dar a conocer periódicamente los datos más relevantes de su actividad, con los elementos económicos y presupuestarios correspondientes, así como facilitar a las personas el acceso a la información pública contenida en documentos y archivos que aquellas custodian”39.

\section{La transparencia en la Directiva 2014/24/UE}

Como hemos indicado, la Unión Europea ha regulado en las diversas Directivas de contratación la transparencia. En este sentido la Directiva 2014/24/UE la regula en numerosos preceptos ${ }^{40}$. El considerando 126 de esta Directiva señala que "la trazabilidad y transparencia de la toma de decisiones en los procedimientos de contratación es fundamental para garantizar unos procedimientos adecuados, incluida la lucha eficaz contra la corrupción y el fraude" ${ }^{41}$. El art. 76 de la Directiva 2014/24/UE incluye la transparencia entre los principios de la contratación ${ }^{42}$.

\section{La transparencia en la normativa contractual española}

Una de las características de la transparencia es la publicidad, y un esbozo de ella ya se recoge en el art. 2 del Decreto de 27 febrero de 1852 al establecer que "toda subasta y remate para servicios y obras públicas se anunciarán con treinta días por lo menos de anticipación por carteles y por medio de la Gaceta del Gobierno y de los Boletines oficiales

39 Diccionario panhispánico del español jurídico, Real Academia Española.

${ }^{40}$ Considerandos 1 ; 45; 52; 58; 59; 61; 68; 73; 80; 82; 90; 105; 110; $112 ; 126$; arts. 40; 56.3 y 76.1.

${ }^{41}$ Vid. el art. 64.1 LCSP.

42 Art. 76 Directiva 2014/24/UE. Principios de adjudicación de contratos: “1. Los Estados miembros establecerán normas nacionales para la adjudicación de los contratos sujetos a lo dispuesto en el presente capítulo, a fin de garantizar que los poderes adjudicadores respetan los principios de transparencia y de igualdad de trato de los operadores económicos”. 
de las provincias respectivas”. ${ }^{43}$ Otro aspecto fundamental de la transparencia es el acceso a los pliegos, y en este sentido el art. 2 señalaba que "al anuncio deberán acompañar los pliegos de condiciones, y cuando esto no sea posible se designará el sitio en que estarán de manifiesto como también las memorias, planos, modelos, muestras y demás objetos, cuyo conocimiento sea necesario para la debida inteligencia de las condiciones”.

En la normativa española se alude a la transparencia en la exposición de motivos de la Ley 13/1995, pero luego no se contempla expresamente en el articulado. Sin embargo, en el TRLCAP no se hace referencia.El principio de transparencia ${ }^{44}$ se enumera ya en el art. 1 de la Ley 30/2007 ${ }^{45}$. De igual modo en el art. 1 del TRLCSP, Ley 24/2011, de 1 de agosto, de contratos del sector público en los ámbitos de la defensa y de la seguridad ${ }^{46} \mathrm{y}$ en el art. 1 de la $\operatorname{LCSP}^{47}$.

\section{Aspectos en que se manifiesta la transparencia}

La transparencia se manifiesta a través de diversos aspectos:

A) En la fase preparatoria del contrato

\section{1.- En las Consultas Preliminares del Mercado (art .115 LCSP)}

La transparencia se traslada también a la fase preparatoria, pues permite que los operadores económicos, a través de la previa publicación en la correspondiente plataforma de contratación, puedan participar en determinados aspectos de la fase preparatoria del contrato.

B) En la fase de licitación

1.- En la publicidad de la licitación ${ }^{48}$.

2.- En la publicación de los pliegos y demás documentos (memoria justificativa de la necesidad del contrato, proyecto técnico, claridad de los criterios de valoración, etc. $)^{49}$.

3.- En la información a los licitadores de las consultas que formulen (art. 138 LCSP $)^{50}$. Pues de este modo, a través de las consultas que se publiquen por escrito en

\footnotetext{
${ }^{43}$ Ya la Sentencia del Tribunal Supremo de 5 de noviembre de 1930 consideró esencial la publicidad en las subastas.

${ }^{44}$ Vid. MORENO MOLINA, J.A., Los principios generales de la contratación de las Administraciones Públicas, editorial Bomarzo, 2006.

${ }^{45}$ Así como en los arts. 42; 123; 175.a); 176.1; 308.2.

${ }^{46}$ Arts. 23; 56; 63.

${ }^{47}$ Así como en los arts. 3.4; 11.6; 63.1; 64.1; 115.2; 132.1; 145.5; 154.7; 166.2; 202.2; 321.1; 321.2; 328.4; 332.6; 346.5; Disp. adicional $3^{\text {a }} .8$.

${ }^{48}$ En la normativa de Contratación se regulaba la exposición de los pliegos para reclamaciones, en este sentido, el Reglamento de 1924, el Reglamento de contratación de las Corporaciones Locales de 1953, el art. 122 del Decreto Legislativo 781/1986, que establecía un plazo de 8 días para reclamaciones, aunque admitía la simultaneidad de la exposición del pliego con la convocatoria (art. 122.2).

${ }^{49}$ Vid. el art. 63.3 LCSP.
} 
cualquier plataforma de contratación, todos los licitadores saben cuál es el criterio interpretativo o aclaratorio del órgano de contratación ante una determinada cláusula en condiciones de igualdad y sin que suponga modificación del pliego.

C) En la fase de adjudicación

\author{
1.- En cuanto a la motivación de la adjudicación ${ }^{51}$ y su notificación y \\ publicación $^{52}$. \\ 2.- En el acceso de la documentación de los demás licitadores ${ }^{53}$, \\ 3.- así como al acceso a la valoración efectuada por los órganos correspondientes \\ de la Administración ${ }^{54}$. \\ 4.- En cuanto a la publicación de la adjudicación ${ }^{55}$.
}

${ }^{50}$ Como manifestación de la transparencia y de la adecuada información a licitadores cabe resaltar la Resolución del TACRC n²74/2020: “... sucede que el propio órgano de contratación, como expresamente reconoce, al responder a la consulta formulada, incurre en error, lo que plantea si con la decisión de excluir al licitador se ha producido una vulneración del principio de buena fe y confianza legítima, al haber actuado el licitador siguiendo las indicaciones de la respuesta a la consulta, y no las previsiones contenidas en el pliego. Sucede que, en el presente caso, otro licitador planteó una consulta, que fue respondida en idéntico sentido a lo preceptuado en los pliegos, resultando igualmente vinculante, de modo que puede entenderse, como afirma el órgano de contratación, que con ello se ha producido una subsanación del error padecido, teniendo en cuenta que tal previsión es plenamente conforme con lo establecido en el pliego. Este Tribunal entiende que la respuesta que refiere el recurrente no tiene la entidad suficiente para haber generado la creencia de que tal respuesta ofrecida alteraba lo establecido en los pliegos, que, como hemos visto, tienen carácter vinculante tanto para los licitadores como para el órgano de contratación. En efecto, los expresados principios de buena fe y de confianza legítima no permiten a la Administración soslayar el carácter vinculante de los pliegos, con quiebra del principio de igualdad de trato a todos los licitadores. Así lo mantiene el Tribunal Supremo, que en sentencia de su Sala III de 27 de abril de 2007, señaló: “También lo es que ese quebrantamiento impondrá el deber de satisfacer las expectativas que han resultado defraudadas, o bien de compensar económicamente el perjuicio de todo tipo sufrido con motivo de la actividad desarrollada por el administrado en la creencia de que su pretensión habría de ser satisfecha; pero no sería correcto deducir de esta doctrina que pueda exigirse a la Administración la efectiva satisfacción de lo demandado cuando ésta haya de ajustarse a una conducta normativamente reglada y se aprecie la ausencia de uno de los requisitos que permitan el otorgamiento de lo solicitado. Es decir: la plena satisfacción de la pretensión desatendida no puede obtenerse en aquellos supuestos en los que está excluido el ejercicio de la potestad discrecional de la Administración y sometida su decisión al cumplimiento de determinados requisitos legales, cuya carencia ha de impedir acceder a lo solicitado. En estos supuestos el quebrantamiento del principio de confianza legítima tan solo podrá llevar consigo la posibilidad de ejercitar una acción de responsabilidad patrimonial por los perjuicios ocasionados al administrado como consecuencia del mismo, procedimiento que ha de seguirse de acuerdo con lo establecido en los artículos $5^{\circ}$ y concordantes del R.D. $429 / 93$ (RCL 1993, 1394 y 1765), que se remite a lo previsto en el artículo 70 de la Ley 30/92 (RCL 1992, 2512, 2775 y RCL 1993, 246) ${ }^{50}$. Esta doctrina se refleja igualmente en las Sentencias del Alto Tribunal de 24 de septiembre de 2009 y 9 de julio de 2012, entre otras”.

${ }^{51}$ Art. 151 LCSP. En este sentido, GARCÍA PÉREZ señala que "la motivación es indiciaria de un modo de realizar la función administrativa encomendada por la Constitución a la Administración Pública. De ahí que esté directamente relacionada con los mandatos de servicio a los intereses generales, objetividad y eficacia recogidos, entre otros, en art. 103.1, y con el propio desarrollo del procedimiento administrativo (art.105), en el que deberá ponerse de manifiesto el iter a través del cual se habrá llegado a tomar la decisión”. GARCÍA PÉREZ. M., "El régimen jurídico de las normas y actos administrativos”, en MEILÁN GIL, J.L. y GARCÍA PÉREZ, M., Norma y actos administrativos, Iustel, $1^{\text {a }}$ edición, 2018, pág. 262.

52 Art. 151 LCSP.

53 Art. 151.2 LCSP.

${ }^{54}$ Art. 152 LCSP.

${ }^{55}$ Art. 154 LCSP. 
5.- En cuanto a la información de los registros de contratos ${ }^{56}$.

D) En la fase de ejecución

Especialmente en lo que se refiere a las modificaciones de los $\operatorname{contratos}^{57}$, prórrogas, certificaciones y facturas, así como actas de recepción o entrega.

\section{Cuando una Administración es transparente}

Entendemos que una Administración es transparente cuando:

$1^{\text {․- }}$ Publica la licitación con la información adecuada, y todos los licitadores tienen conocimiento de la convocatoria y con accesibilidad a pliegos y demás documentos, al mismo tiempo, sin informaciones previas particularizadas o privilegiadas. las ofertas.

$2^{\circ}$.- Cuando se publica la licitación con tiempo suficiente para estudiar y presentar

$3^{\circ}$ - Cuando se justifica adecuadamente la necesidad del contrato, con explicación de los fines de interés público que se persiguen.

$4^{\circ}$ - Cuando se justifica el presupuesto base de licitación, con desglose pormenorizado de los costes directos e indirectos del contrato.

$5^{\circ}$.- Cuando se definen los criterios de valoración de forma objetiva, clara y que permitan a los licitadores conocer sin ningún tipo de dudas qué se les va a valorar y cómo.

$6^{\circ}$.- Cuando se define claramente el objeto del contrato y los derechos y obligaciones de las partes.

$7^{\circ}$.- Cuando se publica la composición del comité de expertos que van a informar el contrato.

$8^{\circ}$.- Cuando se valoran las ofertas de forma motivada y en relación con los criterios establecidos en el pliego y se da acceso a los licitadores a dicha valoración.

$9^{\circ}$.- Cuando se motiva adecuadamente la adjudicación del contrato, se publica y se notifica a todos los licitadores.

$10^{\circ}$.- Cuando cualquier licitador puede acceder a las ofertas de los demás, con la única limitación de la declaración de determinados aspectos de la oferta como confidenciales, como analizaremos más adelante.

$11^{\circ}$.- Cuando publican en el perfil del contratante los aspectos que en el art. 63 LCSP se indican.

$12^{\circ}$.- En el momento de la apertura, especialmente en las aperturas públicas se refuerza el principio de transparencia.

$13^{\circ}$.- En el supuesto de la modificación del contrato, cuando se publica dicha modificación ${ }^{58}$.

$14^{\circ}$.- Cuando se publican las actas de las Mesas de Contratación.

$15^{\circ}$.- Cuando se registran los contratos en el Registro público de contratos.

\footnotetext{
${ }^{56}$ Art. 346 LCSP.

${ }^{57}$ Art. 207 LCSP.

${ }^{58}$ Art. 207 LCSP.
} 


\section{LA CONFIDENCIALIDAD}

El principio de transparencia, que es esencial, en determinadas ocasiones se puede ver limitado en aras al principio de confidencialidad para garantizar que determinada información del licitador que presenta su oferta incluyendo secretos técnicos o comerciales o que afecten a la competencia, pueda llegar al resto de los licitadores, y de esta manera puedan tener acceso a una información que debe estar protegida y que podría ser utilizada por los mismos frente al titular de esos secretos comerciales. La Administración se ve abocada en ocasiones a dilucidar cuál es el interés preponderante, si facilitar el acceso a toda la documentación de los licitadores o restringirla. Las circunstancias a lo largo de un proceso histórico han ido variando. Desde un hermetismo u opacidad total y una falta de motivación o una motivación insuficiente, a una actitud positiva de transparencia, de facilitar una mayor información. Pero siempre se ha tenido en cuenta que el límite a la transparencia está en garantizar también aquella información que debe ser confidencial, y a la que no puede tener acceso otro licitador, pero siempre quedando de manifiesto en el expediente las razones por las que se adjudica un contrato. De ahí que la normativa ha dejado en manos del licitador definir aquellos documentos de su oferta que son confidenciales y cuáles no. También la doctrina de las Juntas consultivas y de los Tribunales de contratación fueron delimitando el alcance de la confidencialidad, que no puede tener carácter absoluto y afectar a toda la oferta, como analizaremos a continuación. Del equilibrio de ambos aspectos, transparencia y confidencialidad, se consigue una contratación garantizadora de derechos y objetiva. En el conflicto entre el derecho de defensa del licitador descartado y el derecho a la protección de los intereses comerciales del licitador adjudicatario, se ha de buscar el necesario equilibrio de forma que ninguno de ellos se vea perjudicado más allá de lo estrictamente necesario.

\section{La confidencialidad en el Derecho Comunitario}

Como estableció la Sentencia del TJUE de 14 de febrero de 2008 (Asunto C450/06, VAREC), al analizar las garantías del órgano que conozca los eventuales procedimientos de recurso, la justificación de este derecho es la siguiente: "El objetivo principal de las normas comunitarias en materia de contratos públicos comprende la apertura a la competencia no falseada en todos los Estados miembros (véase, en este sentido, la sentencia de 11 de enero de 2005, Stadt Halle y RPL Lochau, C-26/03, Rec. p. I1, apartado 44)" ${ }^{59}$. Para lograr dicho objetivo, es necesario que las entidades adjudicadoras no divulguen información relativa a procedimientos de adjudicación de contratos públicos cuyo contenido pueda ser utilizado para falsear la competencia, ya sea en un procedimiento de adjudicación en curso o en procedimientos de adjudicación ulteriores ${ }^{60}$.

59 Citada por el Informe 15/2012, de 19 de septiembre, de la Junta Consultiva de Contratación Administrativa de la Comunidad Autónoma de Aragón.

${ }^{60}$ Añade que: “Además, tanto por su naturaleza como conforme al sistema de la normativa comunitaria en la materia, los procedimientos de adjudicación de contratos públicos se basan en una relación de confianza 
Las Directivas de contratación han regulado la confidencialidad en la contratación $^{61}$. La confidencialidad es un derecho de los licitadores recogido ya en el art. 6 de la Directiva 2004/18/CE ${ }^{62}$, en el apartado 2 del art. 13, en el art. 29 y en el art. 32 de la Directiva 2004/17/CE sobre contratos en los sectores especiales. En la Directiva 2014/24/UE ${ }^{63}$ son numerosas las referencias a la confidencialidad. Entre estos preceptos destacamos el art. 21, que lleva la rúbrica “Confidencialidad”, que indica lo siguiente:

“1. Salvo que se disponga de otro modo en la presente Directiva o en el Derecho nacional a que esté sujeto el poder adjudicador, en particular la legislación relativa al acceso a la información, y sin perjuicio de las obligaciones en materia de publicidad de los contratos adjudicados y de información a los candidatos y a los licitadores establecidas en los artículos 50 y 55, el poder adjudicador no divulgará la información facilitada por los operadores económicos que estos hayan designado como confidencial, por ejemplo, los secretos técnicos o comerciales y los aspectos confidenciales de las ofertas” ${ }^{64}$.

Esta concurrencia de derechos no siempre puede resolverse de manera pacífica: ni la confidencialidad puede comprender la totalidad de la oferta realizada por el

entre las entidades adjudicadoras y los operadores económicos que participan en ellos. Éstos han de poder comunicar a tales entidades adjudicadoras cualquier información útil en el marco del procedimiento de adjudicación, sin miedo a que éstas comuniquen a terceros datos cuya divulgación pueda perjudicar a dichos operadores”. El Tribunal concluye afirmando que este principio de confidencialidad, en contraposición al de acceso a la información, debe interpretarse en el sentido de que el organismo responsable de los procedimientos de recurso: “... debe garantizar la confidencialidad y el derecho a la protección de los secretos comerciales en relación con la información contenida en los expedientes que le comuniquen las partes en la causa, en particular, la entidad adjudicadora, sin perjuicio de que el propio organismo pueda conocer y tomar en consideración dicha información. Corresponde a dicho organismo decidir cómo y en qué medida es preciso garantizar la confidencialidad y el secreto de dicha información, habida cuenta de las exigencias de la protección jurídica efectiva y del respeto al derecho de defensa de las partes en el litigio...”.

${ }^{61}$ La confidencialidad se configura como un derecho fundamental recogido en el art. 41 de la Carta de los derechos fundamentales de la Unión Europea.

${ }^{62}$ En los siguientes términos, art. 6. Confidencialidad: "Sin perjuicio de las disposiciones de la presente Directiva, en particular las relativas a las obligaciones en materia de publicidad de los contratos adjudicados y de información a los candidatos y a los licitadores establecidas en el apartado 4 del artículo 35 y en el artículo 41, y de conformidad con la legislación nacional por la que se rija el poder adjudicador, éste no divulgará la información facilitada por los operadores económicos que éstos hayan designado como confidencial. Dicha información incluye, en particular, los secretos técnicos o comerciales y los aspectos confidenciales de las ofertas". El art. 41 de esta norma, en desarrollo de las normas de publicidad y transparencia aplicables a la información a dar a los candidatos y licitadores por los poderes adjudicadores, recoge en su apartado 3 que los poderes adjudicadores podrán decidir no comunicar determinados datos sobre la adjudicación de los contratos, la celebración de los acuerdos marco o la admisión a un sistema dinámico de adquisición, cuando su difusión pudiera obstaculizar la aplicación de la ley, ser contraria al interés público, o perjudicar los intereses comerciales legítimos de operadores económicos públicos o privados, o perjudicar la competencia leal entre ellos.

${ }^{63}$ Considerando 128; art. 22.3; art. 86.1. En la Directiva 2014/23/UE se alude a ella en el Considerando 60 y arts. 28 y 29.

${ }^{64}$ Añade: "2. Los poderes adjudicadores podrán imponer a los operadores económicos requisitos destinados a proteger el carácter confidencial de la información que los poderes adjudicadores proporcionen durante el procedimiento de contratación”. 
adjudicatario, ni la transparencia puede implicar el acceso incondicionado al expediente de contratación y a los documentos que contiene.

\section{La confidencialidad en la normativa contractual española}

La normativa española tardó en regular la confidencialidad, así, en la Ley 30/2007 se regula por primera vez con amplitud ${ }^{65}$, línea que siguen el TRLCSP, la Ley 24/2011, de 1 de agosto, de contratos del sector público en los ámbitos de la defensa y de la seguridad $^{66}$ y la $\operatorname{LCSP}^{67}$. El art. $133 \operatorname{LCSP}^{68}$ establece el régimen general de la

${ }^{65}$ Arts. 26.1.j; 124; 166.2; 175.a); 176.1; 182.4.c); 308.5; Disp. Adicional 18; Disp. Adicional 19.

${ }^{66}$ Arts. 21.3; 23.2; 33.4; 51.1; 54.3; 60; Disp. Adicional $1^{\text {a }}$.

${ }^{67}$ Arts. 3.4; 35.1.m); 52.1; 56.5; 133; 138.2.b); 169.7; 171; 175.2; 179.6; 180.2; 221.2.c); 221.6.c); 321.1; 328.5; 333.5; 346.5; Disp. adicional 15; Disp. adicional 16.

${ }^{68}$ Art. 133. Confidencialidad: "1. Sin perjuicio de lo dispuesto en la legislación vigente en materia de acceso a la información pública y de las disposiciones contenidas en la presente Ley relativas a la publicidad de la adjudicación y a la información que debe darse a los candidatos y a los licitadores, los órganos de contratación no podrán divulgar la información facilitada por los empresarios que estos hayan designado como confidencial en el momento de presentar su oferta. El carácter de confidencial afecta, entre otros, a los secretos técnicos o comerciales, a los aspectos confidenciales de las ofertas y a cualesquiera otras informaciones cuyo contenido pueda ser utilizado para falsear la competencia, ya sea en ese procedimiento de licitación o en otros posteriores.

El deber de confidencialidad del órgano de contratación, así como de sus servicios dependientes, no podrá extenderse a todo el contenido de la oferta del adjudicatario ni a todo el contenido de los informes y documentación que, en su caso, genere directa o indirectamente el órgano de contratación en el curso del procedimiento de licitación. Únicamente podrá extenderse a documentos que tengan una difusión restringida, y en ningún caso a documentos que sean públicamente accesibles.

El deber de confidencialidad tampoco podrá impedir la divulgación pública de partes no confidenciales de los contratos celebrados, tales como, en su caso, la liquidación, los plazos finales de ejecución de la obra, las empresas con las que se ha contratado y subcontratado, y, en todo caso, las partes esenciales de la oferta y las modificaciones posteriores del contrato, respetando en todo caso lo dispuesto en la Ley Orgánica 15/1999, de 13 de diciembre, de Protección de Datos de Carácter Personal.

2. El contratista deberá respetar el carácter confidencial de aquella información a la que tenga acceso con ocasión de la ejecución del contrato a la que se le hubiese dado el referido carácter en los pliegos o en el contrato, o que por su propia naturaleza deba ser tratada como tal. Este deber se mantendrá durante un plazo de cinco años desde el conocimiento de esa información, salvo que los pliegos o el contrato establezcan un plazo mayor que, en todo caso, deberá ser definido y limitado en el tiempo".

Art. 154. Anuncio de formalización de los contratos: "7. Podrán no publicarse determinados datos relativos a la celebración del contrato cuando se considere, justificándose debidamente en el expediente, que la divulgación de esa información puede obstaculizar la aplicación de una norma, resultar contraria al interés público o perjudicar intereses comerciales legítimos de empresas públicas o privadas o la competencia leal entre ellas, o cuando se trate de contratos declarados secretos o reservados o cuya ejecución deba ir acompañada de medidas de seguridad especiales conforme a la legislación vigente, o cuando lo exija la protección de los intereses esenciales de la seguridad del Estado y así se haya declarado de conformidad con lo previsto en la letra c) del apartado 2 del artículo 19.

En todo caso, previa la decisión de no publicar unos determinados datos relativos a la celebración del contrato, los órganos de contratación deberán solicitar la emisión de informe por el Consejo de Transparencia y Buen Gobierno a que se refiere la Ley 19/2013, de 9 de diciembre, de transparencia, acceso a la información pública y buen gobierno, en el que se aprecie si el derecho de acceso a la información pública prevalece o no frente a los bienes que se pretenden salvaguardar con su no publicación, que será evacuado en un plazo máximo de diez días.

No obstante lo anterior, no se requerirá dicho informe por el Consejo de Transparencia y Buen Gobierno en caso de que con anterioridad se hubiese efectuado por el órgano de contratación consulta sobre una materia 
confidencialidad. En el conflicto entre el derecho de defensa de un licitador descartado, y el derecho de protección de los intereses comerciales del licitador adjudicatario, se ha de buscar el equilibrio adecuado, de forma que ninguno de ellos se vea perjudicado más allá de lo necesario, como ha declarado el TACRC en diversas Resoluciones, entre otras, la nº 199/2011 y la n62/2012 ${ }^{69}$. La doctrina de los Tribunales ha puesto de manifiesto la obligación que incumbe al órgano de contratación de conceder a los interesados en el procedimiento el derecho a información del expediente ${ }^{70}$, concluyendo que "el órgano de contratación deberá conceder el correspondiente acceso al expediente a la empresa recurrente, si bien deberá tener en cuenta la obligación que incumbe al citado órgano de contratación de respetar la debida confidencialidad”71.

\section{Cuestiones a destacar por las juntas consultivas y tribunales administrativos de contratación}

Las Juntas Consultivas de Contratación ${ }^{72}$ y después los Tribunales administrativos de contratación han ido conformado una consolidada doctrina. Algunas cuestiones que merecen destacarse son las siguientes:

a) Persona legitimada para solicitar la declaración de confidencialidad

Es el licitador quien debe designar la declaración de confidencialidad, por escrito en su oferta. En consecuencia, debe tener poder suficiente para formularla, entendiendo que quien tiene facultades para presentar ofertas también las tiene para solicitar la confidencialidad.

b) Momento en que debe designarse como confidencial

Es en el momento de presentar su oferta, en la documentación referida a la licitación a la que concurre. Por lo tanto, no es válido que el licitador dirija una

idéntica o análoga, sin perjuicio de la justificación debida de su exclusión en el expediente en los términos establecidos en este apartado".

${ }^{69}$ Informe 15/2012, de 19 de septiembre, de la Junta Consultiva de Contratación Administrativa de la Comunidad Autónoma de Aragón.

${ }^{70}$ La Resolución $n^{\circ}$ 272/2011 del TACRC ya mantuvo el criterio de que "si bien es cierto que una correcta notificación puede hacer innecesario el acceso al expediente por parte de quienes tengan la condición de interesados en el procedimiento de licitación al objeto de interponer recurso especial suficientemente motivado, ello no exime de la obligación que incumbe al órgano de contratación de conceder a los interesados en el procedimiento el derecho de información del expediente el cual se encuentra amparado por el artículo 35 de la LRJPAC, que en su apartado a) reconoce expresamente el derecho de los ciudadanos "a conocer, en cualquier momento, el estado de tramitación de los procedimientos en los que tengan la condición de interesados, y obtener copias de documentos contenidos en ellos".

${ }^{71}$ Vid. Resoluciones n²2/2018; 36/2018; 63/2018; 98/2018 del TARC de Castilla y León.

72 Junta Consultiva de contratación Administrativa de la Comunidad Autónoma de Aragón, Informe 15/2012 de 19 de septiembre; Junta Consultiva de Contratación Administrativa de la Generalitat de Cataluña, Informe 11/2013 de 26 de julio; Junta Consultiva de Contratación Administrativa de la Comunidad de Madrid, Informe 6/2016, de 12 de septiembre. 
comunicación genérica a la Administración indicando que en todas las licitaciones a las que concurra en el futuro sus ofertas tienen carácter confidencial. Entendemos igualmente que si no ha declarado un documento como confidencial no puede hacerlo a posteriori.

c) Necesidad de que la designación de confidencialidad se realice con carácter previo, es decir, en la propia proposición

La LCSP atribuye en primer lugar la designación de la confidencialidad al licitador en su oferta y debemos destacar que si no ha designado ningún documento como confidencial no lo puede hacer a posteriori. En esta línea, la Resolución n³63/2020 del TACRC ha señalado que "la protección de los aspectos y partes de las proposiciones presentadas que pudieran ser confidenciales o merecieran una protección de tal tipo la encomienda la vigente LCSP, en primer lugar y con carácter esencial, al propio interesado en esa información y datos, que es el licitador. Esa protección, además, ha de efectuarla anticipadamente, con carácter previo, es decir, en la propia proposición cuando todavía nadie pretende el acceso a esa información, mediante la indicación concreta de qué documentos o partes de los mismos o información tiene ese carácter de confidencial o protegido por la declaración de confidencialidad, tal y como dispone el artículo 133.1 de la LCSP. Quiere ello decir que si el propio interesado no ha efectuado esa indicación o declaración de confidencialidad o no ha concretado la información que es confidencial en la misma proposición, el contenido de ésta no es, en principio, confidencial, por lo que el órgano de contratación no tiene deber alguno de amparar una confidencialidad inexistente respecto de una información que no ha sido protegida, si concurren los requisitos legales por el propio interesado concernido. En el expediente examinado no se ha encontrado documento designado confidencial por el adjudicatario”.

d) Órgano a quien corresponde la obligación de no divulgación de la información

Le corresponde al órgano de contratación la obligación de no divulgación de la documentación designada como confidencial por los licitadores. No obstante, recae también sobre dicho órgano de contratación la compleja obligación de decidir -en aquellos supuestos en que los licitadores extienden el carácter confidencial a toda su oferta- cuál es la documentación o información concreta que tendrá carácter confidencial, que deberá realizar de forma debidamente motivada y justificada.

e) El carácter no absoluto del principio de confidencialidad ni el de publicidad

El TACRC se ha pronunciado en varias ocasiones al respecto. Así, en la Resolución n¹49/2018 reitera que: "Ni el principio de confidencialidad es absoluto, ni tampoco lo es el de publicidad. El principio de confidencialidad es una excepción al principio de acceso al expediente que se configura como una garantía del administrado en el momento de recurrir. Como tal excepción debe hallarse justificada por la necesidad de protección de determinados intereses, correspondiendo a quien ha presentado los 
documentos cuyo acceso se quiere limitar la carga de declarar su confidencialidad. El TACRC viene entendiendo que, en el conflicto entre el derecho de defensa del licitador descartado y el derecho a la protección de los intereses comerciales del licitador adjudicatario, se ha de buscar el necesario equilibrio de forma que ninguno de ellos se vea perjudicado más allá de lo estrictamente necesario”73.

f) La declaración de confidencialidad no puede abarcar la totalidad de la oferta

Esta declaración de confidencialidad referida a la totalidad de su oferta técnica contraviene lo establecido tanto en la legislación como en la diversa doctrina al respecto (Resoluciones n³43/2015, 45/2013 o 62/2012 del Tribunal Administrativo Central de Recursos Contractuales, entre otras). Tal y como declara el ya citado art. 133.1 de la LCSP, el deber de confidencialidad del órgano de contratación, así como de sus servicios dependientes no podrá extenderse a todo el contenido de la oferta del adjudicatario.

g) Información a la que afecta la confidencialidad

El carácter de confidencial afecta, entre otros, a los secretos técnicos o comerciales, a los aspectos confidenciales de las ofertas y a cualesquiera otras informaciones cuyo contenido pueda ser utilizado para falsear la competencia, ya sea en ese procedimiento de licitación o en otros posteriores. Como señala la Resolución nº682/2020 del TACRC ${ }^{74}$ "El carácter confidencial de la documentación no puede señalarse de forma genérica sobre la totalidad de la documentación, debiendo venir referida a secretos técnicos o comerciales, como aquella documentación confidencial que comporta una ventaja competitiva, desconocida por terceros y que, representando un valor estratégico para la empresa, afecte a su competencia en el mercado, siendo obligación del licitador que invoca el deber de confidencialidad justificar suficientemente que la documentación aportada es verdaderamente confidencial y al órgano de contratación decidir de forma motivada (Resolución n58/2018)”. Entendemos que debería establecerse una aplicación informática en la correspondiente Plataforma de contratación que facilite el acceso a los documentos o aspectos no confidenciales de las ofertas, pues cuando un licitador accede a un expediente de otro licitador que contiene datos confidenciales tiene que proceder la Administración previamente a preparar su no visibilidad con la complejidad y dificultades que ello comporta. La cuestión más importante es la de concretar cuál es la información que debe considerarse confidencial $^{75}$. También es confidencial aquella información que afecta a aspectos confidenciales, por la posibilidad de que se perjudiquen intereses legítimos o la competencia leal entre empresas, como los secretos técnicos o comerciales, las propuestas

${ }^{73}$ Resoluciones 199/2011 y 62/2012.

${ }^{74}$ Citando la Resolución n ${ }^{\circ} 616 / 2019$, de 6 de junio.

75 "La doctrina considera información confidencial a los efectos que venimos enjuiciando aquella que afecte a secretos técnicos o comerciales, como por ejemplo la documentación relativa a las características técnicas específicas de un nuevo producto, las líneas generales de una campaña publicitaria estratégica, una fórmula, un compuesto químico, el modelo para una máquina o el nombre de una empresa que se pretende absorber, pero no la relación de trabajos, trabajadores, maquinaria, facturación o cuenta de resultados”. 
de ejecución que contienen políticas empresariales que constituyen la estrategia original de la empresa y que no debe ser conocida por los competidores, su formulación original de carácter técnico, de articulación de medios humanos o de introducción de patentes propias (Acuerdo TACP Aragón 10/2015). En este sentido, cabe recordar que la jurisprudencia ha concretado el concepto de secretos técnicos o comerciales como el conjunto de conocimientos que no son de dominio público y que resultan necesarios para la fabricación o comercialización de productos, la prestación de servicios, y la organización administrativa o financiera de una unidad o dependencia empresarial, y que por ello procura a quien dispone de ellos de una ventaja competitiva en el mercado que se esfuerza en conservar en secreto, evitando su divulgación. La confidencialidad deriva de la posibilidad de que se perjudiquen intereses legítimos o a la competencia leal entre empresas, de modo que, como señala el acuerdo n¹06/2015 del TACP de Madrid los requisitos para calificar de confidencial la documentación presentada por los licitadores son los siguientes: “a) que comporte una ventaja competitiva para la empresa, b) que se trate de una información verdaderamente reservada, es decir, desconocida por terceros, c) que represente un valor estratégico para la empresa y pueda afectar a su competencia en el mercado y d) que no se produzca una merma en los intereses que se quieren garantizar con los principios de publicidad y de transparencia” ${ }^{76}$.

Igualmente debe traerse a colación el art. 133 de la LCSP: “1. Sin perjuicio de lo dispuesto en la legislación vigente en materia de acceso a la información pública y de las disposiciones contenidas en la presente Ley relativas a la publicidad de la adjudicación y a la información que debe darse a los candidatos y a los licitadores, los órganos de contratación no podrán divulgar la información facilitada por los empresarios que estos hayan designado como confidencial en el momento de presentar su oferta. El carácter de confidencial afecta, entre otros, a los secretos técnicos o comerciales, a los aspectos confidenciales de las ofertas y a cualesquiera otras informaciones cuyo contenido pueda ser utilizado para falsear la competencia, ya sea en ese procedimiento de licitación o en otros posteriores. (...)”.

Entendemos que, a efectos de la Ley de Contratos, se deberían acotar más estos conceptos mediante su referencia a la normativa sectorial o específica, así, la Ley de Secretos Empresariales ${ }^{77}$ da una definición de secreto empresarial, siguiendo la línea de la Directiva (UE) 2016/943 del Parlamento Europeo y del Consejo, de 8 de junio de 2016,

${ }^{76}$ En igual sentido, Resolución nº656/2020 del TACRC.

${ }^{77}$ Art. 1. Objeto:

“1. El objeto de la presente ley es la protección de los secretos empresariales. A efectos de esta ley, se considera secreto empresarial cualquier información o conocimiento, incluido el tecnológico, científico, industrial, comercial, organizativo o financiero, que reúna las siguientes condiciones:

a) Ser secreto, en el sentido de que, en su conjunto o en la configuración y reunión precisas de sus componentes, no es generalmente conocido por las personas pertenecientes a los círculos en que normalmente se utilice el tipo de información o conocimiento en cuestión, ni fácilmente accesible para ellas;

b) tener un valor empresarial, ya sea real o potencial, precisamente por ser secreto, y

c) haber sido objeto de medidas razonables por parte de su titular para mantenerlo en secreto". 
relativa a la protección de los conocimientos técnicos y la información empresarial no divulgados contra su obtención, utilización y revelación ilícitas ${ }^{78}$.

h) Divulgación de las partes no confidenciales de la oferta

El deber de confidencialidad tampoco podrá impedir la divulgación pública de partes no confidenciales de los contratos celebrados, tales como, en su caso, la liquidación, los plazos finales de ejecución de la obra, las empresas con las que se ha contratado y subcontratado, y, en todo caso, las partes esenciales de la oferta y las modificaciones posteriores del contrato, respetando en todo caso lo dispuesto en la Ley Orgánica 15/1999, de 13 de diciembre, de Protección de Datos de Carácter Personal ${ }^{79}$.

i) Respeto por parte del contratista de la documentación confidencial a la que tenga acceso por la ejecución del contrato

El contratista deberá respetar el carácter confidencial de aquella información a la que tenga acceso con ocasión de la ejecución del contrato a la que se le hubiese dado el referido carácter en los pliegos o en el contrato, o que por su propia naturaleza deba ser tratada como tal. Este deber se mantendrá durante un plazo de cinco años desde el conocimiento de esa información, salvo que los pliegos o el contrato establezcan un plazo mayor que, en todo caso, deberá ser definido y limitado en el tiempo.

j) No publicación de determinados datos relativos a la celebración del contrato

En determinadas circunstancias, el legislador prevé que no se publique determinada información relativa a la celebración del contrato. Así, el art. 154 establece la obligación de publicar determinada información relativa a la celebración del contrato. Sin embargo, en su apartado siete señala que podrán no publicarse determinados datos relativos a la celebración del contrato cuando se considere, justificándose debidamente en el expediente, que la divulgación de esa información:

1.- puede obstaculizar la aplicación de una norma,

2.- resultar contraria al interés público o perjudicar intereses comerciales legítimos de empresas públicas o privadas

3.- o la competencia leal entre ellas,

${ }^{78}$ A los efectos de la presente Directiva se entenderá por:

“1) ‘secreto comercial’: la información que reúna todos los requisitos siguientes:

a) ser secreta en el sentido de no ser, en su conjunto o en la configuración y reunión precisas de sus componentes, generalmente conocida por las personas pertenecientes a los círculos en que normalmente se utilice el tipo de información en cuestión, ni fácilmente accesible para estas;

b) tener un valor comercial por su carácter secreto;

c) haber sido objeto de medidas razonables, en las circunstancias del caso, para mantenerla secreta, tomadas por la persona que legítimamente ejerza su control”.

${ }^{79}$ Ahora Ley Orgánica 3/2018, de 5 de diciembre, de Protección de Datos Personales y garantía de los derechos digitales. 
4.- o cuando se trate de contratos declarados secretos o reservados o cuya ejecución deba ir acompañada de medidas de seguridad especiales conforme a la legislación vigente,

5.- o cuando lo exija la protección de los intereses esenciales de la seguridad del Estado y así se haya declarado de conformidad con lo previsto en la letra c) del apartado 2 del art. 19.

\section{k) Solicitud de informe del Consejo de Transparencia y Buen Gobierno}

La decisión de no publicar determinados datos de la formalización del contrato la toma el órgano de contratación, pero requiere que éste solicite informe al Consejo de Transparencia y Buen Gobierno ${ }^{80}$. Entendemos que, aunque la LCSP no lo dice, las Comunidades Autónomas o entidades locales podrán solicitar igualmente este informe a los órganos de transparencia de las Comunidades Autónomas.

l) Supuesto en que no se requiere informe del Consejo de Transparencia y Buen Gobierno

Existe una excepción a la solicitud de informe del citado Consejo que se da en el supuesto en que el órgano de contratación con anterioridad hubiese efectuado una consulta sobre una materia idéntica o análoga ${ }^{81}$.

m) Garantía de confidencialidad en el recurso especial en materia de contratación

La LCSP establece una garantía de la confidencialidad en los supuestos de presentación del recurso especial en materia de contratación, atribuyendo al órgano competente para resolver el recurso garantizar dicha confidencialidad ${ }^{82}$, sin que ello perjudique al derecho de defensa en el procedimiento. En los Reglamentos de los

${ }^{80}$ En todo caso, previa la decisión de no publicar unos determinados datos relativos a la celebración del contrato, los órganos de contratación deberán solicitar la emisión de informe por el Consejo de Transparencia y Buen Gobierno a que se refiere la Ley 19/2013, de 9 de diciembre, de transparencia, acceso a la información pública y buen gobierno, en el que se aprecie si el derecho de acceso a la información pública prevalece o no frente a los bienes que se pretenden salvaguardar con su no publicación. El plazo máximo para evacuar el informe será de diez días.

${ }^{81}$ Art. 154.7 LCSP: “no se requerirá dicho informe por el Consejo de Transparencia y Buen Gobierno en caso de que con anterioridad se hubiese efectuado por el órgano de contratación consulta sobre una materia idéntica o análoga, sin perjuicio de la justificación debida de su exclusión en el expediente en los términos establecidos en este apartado”.

82 Art. 56.5 Ley 9/2017: “El órgano competente para la resolución del recurso deberá, en todo caso, garantizar la confidencialidad y el derecho a la protección de los secretos comerciales en relación con la información contenida en el expediente de contratación, sin perjuicio de que pueda conocer y tomar en consideración dicha información a la hora de resolver.

Corresponderá a dicho órgano resolver acerca de cómo garantizar la confidencialidad y el secreto de la información que obre en el expediente de contratación, sin que por ello, resulten perjudicados los derechos de los demás interesados a la protección jurídica efectiva y al derecho de defensa en el procedimiento”. 
Tribunales también se regulan estos aspectos (TACRC) ${ }^{83}$. El derecho de acceso se extiende a lo que constituye el expediente, tal y como viene definido en el art. 70 de la Ley 39/2015, de 1 de octubre, de procedimiento administrativo común, no extendiéndose a otros documentos que, aun cuando hubieran sido aportados por los licitadores, no hayan servido de antecedente de la resolución impugnada (Resolución $n^{\circ} 732 / 2016$ ). La confidencialidad únicamente puede propugnarse de documentos que sean verdaderamente secretos, es decir, que no resulten accesibles o puedan ser consultados por terceros (Resolución n³93/2016). En todo caso, "el derecho de acceso al expediente tiene un carácter meramente instrumental, vinculado a la debida motivación de la resolución de adjudicación como presupuesto del derecho de defensa del licitador descartado, por lo que no es imprescindible dar vista del expediente al recurrente más que en aquellos aspectos respecto de los cuales quede justificada la necesidad de su conocimiento para fundar el recurso (Resolución n'741/2018)”.

n) El derecho de acceso al expediente como derecho instrumental vinculado a la resolución impugnada

La Resolución n¹44/2020, de 30 de enero de 2020, del TACRC señalaba que este Tribunal se ha pronunciado sobre el trámite de vista del expediente en diversas ocasiones, afirmando su carácter instrumental. Así, en la Resolución 131/2015, de 6 de febrero, con cita de la Resolución 852/2014 expone que "En tanto dicho acceso tiene un carácter meramente instrumental (vinculado a la debida motivación de la resolución como

83 Real Decreto 814/2015, de 11 de septiembre, por el que se aprueba el Reglamento de los procedimientos especiales de revisión de decisiones en materia contractual y de organización del Tribunal Administrativo Central de Recursos Contractuales:

Art. 16. Acceso al expediente de contratación: “1. Si el interesado desea examinar el expediente de contratación de forma previa a la interposición del recurso especial, deberá solicitarlo al órgano de contratación, el cual tendrá la obligación de ponerlo de manifiesto sin perjuicio de los límites de confidencialidad establecidos en los artículos 140 y 153 del texto refundido de la Ley de Contratos del Sector Público.

La solicitud de acceso al expediente podrán hacerla los interesados dentro del plazo de interposición del recurso especial, debiendo el órgano de contratación facilitar el acceso en los cinco días hábiles siguientes a la recepción de la solicitud.

2. El incumplimiento de las previsiones contenidas en el apartado anterior por el órgano de contratación no eximirá a los interesados de la obligación de interponer el recurso especial dentro del plazo establecido en el artículo 44.2 del texto refundido de la Ley de Contratos del Sector Público. Ello no obstante, el citado incumplimiento podrá ser alegado por el recurrente en su recurso con los efectos establecidos en el artículo 29.4 del presente reglamento”.

También se refiere a la confidencialidad el art. 28. Remisión del expediente: “1. El expediente de contratación se remitirá por medios electrónicos siempre que sea posible.

2. Se enviará el expediente de contratación completo y ordenado, acompañado de un índice de los documentos que contenga, incluyendo diligencia de autenticación. Deberá añadirse necesariamente a aquél una relación de los participantes en la licitación con su número de identificación fiscal. En el caso de las uniones temporales de empresas se incluirán los números de identificación fiscal correspondientes a cada una de las entidades que, en su momento, la hayan de constituir.

En el expediente se incluirán los documentos declarados confidenciales por los licitadores haciendo constar su carácter confidencial en el índice y en el lugar del expediente donde se encuentren dichos documentos”. 
presupuesto del derecho de defensa del licitador descartado, tal y como se ha dicho antes) y dado que la forma habitual de dar conocimiento a los interesados de la motivación del acto adjudicando el contrato es la notificación del mismo, no sería imprescindible dar vista del expediente al futuro reclamante más que en aquellos aspectos respecto de los cuales quede justificada la necesidad de su conocimiento para fundar la reclamación, no obstante la motivación plasmada en la notificación”. Como pone de manifiesto la Resolución n487/2020 del TACRC “el artículo 52 de la LCSP que invocan las recurrentes. ${ }^{84}$ (...) "tal precepto debe ponerse en conexión con el artículo 56.5 de la LCSP, al amparo del cual: "El órgano competente para la resolución del recurso deberá, en todo caso, garantizar la confidencialidad y el derecho a la protección de los secretos comerciales en relación con la información contenida en el expediente de contratación, sin perjuicio de que pueda conocer y tomar en consideración dicha información a la hora de resolver. Corresponderá a dicho órgano resolver acerca de cómo garantizar la confidencialidad y el secreto de la información que obre en el expediente de contratación, sin que, por ello, resulten perjudicados los derechos de los demás interesados a la protección jurídica efectiva y al derecho de defensa en el procedimiento”.

\section{ñ) Principio de confidencialidad bidireccional}

La doctrina de los Tribunales de Contratación ha remarcado el principio de confidencialidad bidireccional $^{85}$. El deber de confidencialidad del órgano de contratación, así como de sus servicios dependientes, no podrá extenderse a todo el contenido de la oferta del adjudicatario ni a todo el contenido de los informes y documentación que, en su caso, genere directa o indirectamente el órgano de contratación en el curso del procedimiento de

${ }^{84}$ Conforme al mismo: "1. Si el interesado desea examinar el expediente de contratación de forma previa a la interposición del recurso especial, deberá solicitarlo al órgano de contratación, el cual tendrá la obligación de ponerlo de manifiesto sin perjuicio de los límites de confidencialidad establecidos en la Ley.

2. Los interesados podrán hacer la solicitud de acceso dentro del plazo de interposición del recurso especial, debiendo el órgano de contratación facilitar el acceso en los cinco días hábiles siguientes a la recepción de la solicitud. La presentación de esta solicitud no paralizará en ningún caso el plazo para la interposición del recurso especial.

3. El incumplimiento de las previsiones contenidas en el apartado 1 anterior no eximirá a los interesados de la obligación de interponer el recurso especial dentro del plazo legalmente establecido. Ello no obstante, el citado incumplimiento podrá ser alegado por el recurrente en su recurso, en cuyo caso el órgano competente para resolverlo deberá conceder al recurrente el acceso al expediente de contratación en sus oficinas por plazo de diez días, con carácter previo al trámite de alegaciones, para que proceda a completar su recurso. En este supuesto concederá un plazo de dos días hábiles al órgano de contratación para que emita el informe correspondiente y cinco días hábiles a los restantes interesados para que efectúen las alegaciones que tuvieran por conveniente".

${ }^{85}$ Como señaló el TACRC en la Resolución nº196/2016, de 11 de marzo de 2016, la normativa "consagra el denominado principio de confidencialidad bidireccional, que en la vertiente relativa a la información suministrada por el contratista garantiza la protección de los secretos técnicos o comerciales y de los aspectos confidenciales de las ofertas, de modo que el órgano de contratación debe respetar esa información y no divulgarla. Como es sabido por las partes, este principio está matizado por las disposiciones relativas a la publicidad de la adjudicación y a la información que debe darse a los candidatos y a los licitadores a los efectos de poder fundar suficientemente su recurso, de modo que debe existir un equilibrio razonable y prudente entre estos dos principios de la contratación pública”. 
licitación. Únicamente podrá extenderse a documentos que tengan una difusión restringida, y en ningún caso a documentos que sean públicamente accesibles.

o) La motivación de la adjudicación y su notificación. Necesidad de conocimiento de aquellos aspectos para fundamentar la reclamación

La forma habitual de dar conocimiento a los interesados de la motivación del acto adjudicando el contrato es la notificación del mismo y por ello "no sería imprescindible dar vista del expediente al futuro reclamante más que en aquellos aspectos respecto de los cuales quede justificada la necesidad de su conocimiento para fundar la reclamación, no obstante la motivación plasmada en la notificación”86. En esta misma línea, en la Resolución 248/2015 del TACRC señalaba que "alguno de los recurrentes también ha manifestado que el órgano de contratación no le ha permitido tener acceso al contenido completo del expediente incluso una vez efectuada la adjudicación, ocultándose, en particular, la documentación presentada por la finalmente adjudicataria, con lo que no ha sido posible rebatir adecuadamente los argumentos de los técnicos en el recurso. Pues bien, tal derecho encuentra su fundamento en la necesidad de conocer los elementos de juicio que han servido de fundamento al acto impugnado, por lo que debe ser considerado como de carácter subsidiario respecto de la obligación de notificar adecuadamente el mismo. En el caso que venimos contemplando a lo largo de esta resolución, la adjudicación, único acto impugnado por todos los recurrentes, ha sido notificado cumpliendo los requisitos del artículo 151.4 TRLCSP puesto que junto a la puntuación otorgada a cada uno de los licitadores se ha acompañado el informe de valoración, como así se deduce del propio conocimiento del mismo que ponen estos de manifiesto en sus escritos de recurso. En tales circunstancias, el órgano de contratación no está obligado a facilitar el acceso al expediente, salvo que la impugnación verse sobre aspectos no notificados. Del precepto y doctrina transcritos, se infiere que el órgano de contratación sólo está obligado a guardar reserva, y, por lo tanto, a denegar el acceso, respecto de la información que los propios licitadores han designado como confidencial al presentar su oferta, declaración que, por lo demás, no puede extenderse a la totalidad de la misma ${ }^{87 \text { ”. }}$

${ }^{86}$ Así, en la Resoluciones del TACRC n655/2017, de 21 de julio, 131/2015 y 852/2014.

87 Añade esta Resolución que “en el caso que nos ocupa, la adjudicataria no determinó al presentar la oferta qué documentos de los presentados eran confidenciales, sino que lo hizo a requerimiento del órgano de contratación que, a su vez, le hizo el requerimiento debido a la solicitud de acceso al expediente que había realizado la empresa ahora recurrente, antes de que se produjera la adjudicación. Dado que, en su contestación, el adjudicatario se limitó a indicar qué documentos se consideraban confidenciales, sin aportar ninguna justificación, el órgano de contratación volvió a requerir a la empresa para que razonase su calificación, lo que llevó a cabo en escrito de 4 de enero de 2018. El órgano de contratación no realizó pronunciamiento expreso, limitándose tácitamente a aceptar la declaración de confidencialidad de B. D., S.A., y dando acceso a la ahora recurrente a la parte del expediente que no había recibido aquella consideración por la adjudicataria. Es evidente que lo actuado no se ajusta a lo normativamente previsto. Sin embargo, no procede anular la resolución con retroacción de actuaciones con el fin de que se resuelva por el órgano de contratación sobre la confidencialidad o no de los documentos indicados como tal por la empresa y, en su caso, se dé acceso a la recurrente para que pueda completar su recurso, pues como hemos visto, el acceso al expediente no es un derecho absoluto sino que tiene carácter instrumental, su finalidad es permitir a la empresa perjudicada por la resolución de adjudicación conocer exactamente las razones por las que ésta se 
Con base en la doctrina expuesta, debe concluirse que la cuestión esencial es que el acceso al expediente no es un derecho absoluto, sino que tiene carácter instrumental para permitir al recurrente conocer exactamente las razones por las que el órgano dictó el acto correspondiente y poder combatirlo fundadamente. Y si bien, como regla general se debe facilitar a los licitadores el contenido de las decisiones que tengan efecto determinante sobre la resolución del procedimiento de adjudicación por aplicación de los principios de publicidad y transparencia, este deber se cumple a través de la notificación de la adjudicación, que debe incorporar una motivación suficiente que posibilite la interposición de un recurso suficientemente fundado. No se reconoce, por tanto y con carácter general, un derecho de acceso al expediente mediante la solicitud de vista ni de copias del mismo. De hecho, el Tribunal sólo viene reconociendo tal acceso como exigible cuando la motivación de la resolución sea insuficiente y únicamente (como se advertía en la propia Resolución 131/2015, citando a su vez a la Resolución 852/2014) en aquellos concretos aspectos respecto de los cuales quede justificada la necesidad de su conocimiento para fundar la reclamación ${ }^{88}$.

\section{p) Aspectos concretos de la confidencialidad}

1. Confidencialidad del informe de justificación de la oferta anormalmente baja. Los Tribunales Administrativos de Contratación se pronuncian por el carácter confidencial de los documentos de justificación de las ofertas anormalmente bajas cuando estén relacionadas con la documentación que designaron como confidencial en su oferta y vinculados a secretos comerciales ${ }^{89}$.

dictó y poder combatirla fundadamente. Sin embargo, con independencia de que fuera procedente o no mantener la confidencialidad de algunos o todos los documentos considerados como tal, lo cierto es que el recurrente ha podido articular su oposición a la valoración de las ofertas, como se revela en la exposición que hemos realizado en el fundamento de derecho cuarto de esta resolución de las alegaciones del recurso. No se ha vulnerado su derecho a la defensa, por lo que no procede retrotraer las actuaciones por un incumplimiento puramente formal del procedimiento".

88 "En el caso analizado, debe tenerse presente que las entidades recurrentes han tenido acceso a los documentos necesarios para la adecuada preparación de una eventual reclamación frente al acuerdo de adjudicación, constatando este Tribunal que la denegación parcial del acceso ha sido razonable, atendiéndose previamente al conflicto entre el derecho de defensa del licitador descartado y el derecho a la protección de los intereses comerciales del licitador adjudicatario, habiendo así buscado el necesario equilibrio entre ambos derechos, de forma que ninguno de ellos se vea perjudicado más allá de lo estrictamente necesario. En consecuencia, consideramos que no se ha vulnerado su derecho a la defensa, y por consiguiente no procedería conceder a las recurrentes el acceso a tales documentos por encontrarnos ante un incumplimiento puramente formal del procedimiento que en ningún caso le ha causado indefensión”.

${ }^{89}$ Resolución nº488/2020 del TACRC: "en el expediente examinado se observa que el adjudicatario designó como confidencial parte de la documentación aportada para justificar su oferta (se hace referencia en concreto a la documentación aportada salvo los anexos 1, 12 a 20, es decir, parte de la documentación aportada para justificar la baja en la oferta) por contener datos de comercialización, venta, distribución y producción, sensibles. En concreto se discriminan los documentos aportados y se indica que parte de ellos integran secretos comerciales cuyo conocimiento general quebrantaría las reglas de competencia entre empresas razón por la que los declara con carácter confidencial. Dicha aclaración a nuestro juicio reúne los requisitos establecidos en la norma y en la doctrina para hacer prevalecer la confidencialidad sobre la publicidad y transparencia en el seno del proceso de contratación”. 
2. Acceso a solvencia. Datos de facturas. Se ha planteado la cuestión sobre si se puede dar información de acceso a facturas. Como señala la Resolución nº403/2020 TACRC: "En primer lugar, se indica que la confidencialidad, con carácter general, no puede afectar a la solvencia, y, singularmente, a la relación de trabajos tomados en consideración. Esta afirmación se matiza, en segundo lugar, mediante la distinción entre clientes públicos y clientes privados. La confidencialidad no podría abarcar los suministros prestados a los sujetos públicos. La única duda podría suscitarse respecto de los servicios prestados a particulares, pues los datos sobre la clientela, en determinadas circunstancias, se han entendido comprendidos en el secreto de empresa" 90 . Según indica un licitador, "el motivo de dicha consideración se debió a que la documentación que aportamos para acreditar la realización de las prestaciones, eran facturas emitidas a nuestros clientes privados, donde figuran los precios unitarios de distintos equipos de aire acondicionado, condiciones de pago, y entendemos que dicha información es parte de los secretos comerciales de la empresa, cuya divulgación a otros licitadores y a terceros, puede afectar al falseamiento de la competencia tanto en otros procedimientos de licitación como en sus relaciones comerciales con entidades privadas, pudiéndonos poner en desventaja con otros competidores del sector”.

3. Confidencialidad de maqueta técnica. Se ha planteado la cuestión de si una maqueta técnica reviste carácter confidencial. En este sentido, el TACRC entiende que "la parte a la que no se dio acceso y, en concreto, la maqueta técnica presentada por B.S. I. S.L., reviste carácter confidencial dado que muestra el detalle de los desarrollos particularizados en cuanto a la gestión de personal, en concreto en lo relativo al filtro exportación y detalles personalizados, por lo que entendemos que la visualización de estos aspectos por la recurrente, podrían afectar a la competencia en el mercado de la empresa B.S. I. S.L., en cuanto suponen una ventaja competitiva en su manera de obtener el máximo de opciones de la herramienta usada (ODOO) y por ello, no tendría sentido permitir la instalación y despliegue de la maqueta a la recurrente en formato digital, en cuanto a que permitiría conocer todos los detalles de la citada implementación, además de las técnicas utilizadas para realizar el desarrollo, que forman parte del valor estratégico de la otra empresa licitadora" ${ }^{91}$.

En este sentido cabe señalar la Resolución n58/2018 del Tribunal Administrativo Central de Recursos Contractuales, que hace referencia a la Resolución n¹96/2016 del mismo Tribunal, en la que se estableció que "se consideran secretos técnicos o comerciales el "conjunto de conocimientos que no son de dominio público y que resultan necesarios para la fabricación o comercialización de productos, la prestación de servicios, y la organización administrativa o financiera de una unidad o dependencia empresarial, y que por ello procura a quien dispone de ellos de una ventaja competitiva en el mercado que se esfuerza en conservar en secreto, evitando su divulgación” y se señaló que para que la

\footnotetext{
90 Auto TJCE de 30 de marzo de 1982 - C-236/81.

${ }^{91}$ Resolución n³69/2020 del TACRC.
} 
documentación sea verdaderamente confidencial, es necesario que se trate de documentación que “a) que comporte una ventaja competitiva para la empresa, b) que se trate de una información verdaderamente reservada, es decir, desconocida por terceros, c) que represente un valor estratégico para la empresa y pueda afectar a su competencia en el mercado".

Entendemos que el órgano de contratación ha actuado correctamente, con arreglo tanto al art. 52, como al 133 de la LCSP, ya que en ningún caso se ha denegado el acceso al expediente de manera genérica o indiscriminada, sino solamente a la parte de la oferta técnica calificada como confidencial. Por dicho motivo, "no cabe entender que exista indefensión ni quebrantamiento del derecho de defensa que alega la recurrente, máxime cuando aun no teniendo acceso a la maqueta técnica, ello no le ha impedido defenderse en derecho y formular su recurso criticando con extensión tanto el informe técnico de fecha 25 de noviembre de 2019 (que la recurrente cita errónea y repetidamente como informe de 29 de noviembre en su escrito), como la oferta presentada por la otra licitadora" 92.

\section{CONTRATACIÓN PÚBLICA Y PROTECCIÓN DE DATOS PERSONALES}

La inclusión de cláusulas relativas a protección de datos en la normativa contractual arranca de la Ley $30 / 2007^{93}$. La protección de datos personales en la contratación pública ha sido reforzada mediante el Real Decreto-ley 14/2019, de 31 de octubre $^{94}$, en coherencia con el Reglamento (UE) 2016/679 del Parlamento Europeo y del Consejo de 27 de abril de 2016 ${ }^{95}$. La Ley Orgánica 3/2018, de 5 de diciembre, de Protección de Datos Personales y garantía de los derechos digitales derogó la Ley Orgánica 15/1999, de 13 de diciembre, de Protección de Datos de Carácter Personal, y por ello las referencias a la ley derogada deben entenderse referidas a la nueva ley. Abarca diversos aspectos:

\section{La protección de datos en la fase de preparación del contrato}

\subsection{En los pliegos de cláusulas administrativas particulares ${ }^{96}$}

Los pliegos deberán mencionar expresamente la obligación del futuro contratista de respetar la normativa vigente en materia de protección de datos. Sin perjuicio de lo establecido en el art. 28.2 del Reglamento (UE) 2016/679 del Parlamento Europeo y del Consejo, de 27 de abril de 2016, relativo a la protección de las personas físicas en lo que respecta al tratamiento de datos personales y la libre circulación de estos datos y por el que

\footnotetext{
92 Ibidem.

93 Art. 308.5; Disp. adicional 18.3; Disp. adicional 31.

${ }^{94}$ Por el que se adoptan medidas urgentes por razones de seguridad pública en materia de administración digital, contratación del sector público y telecomunicaciones.

${ }^{95}$ Es de interés el Dictamen CNS 1/2019 de la Autoridad Catalana de Protección de Datos (APDCAT), así como la Nota informativa 1/2019. Cumplimiento del deber de transparencia y de la normativa de protección de datos personales en la contratación pública de la Secretaría Técnica de la Junta Consultiva de Contratación Administrativa de la Generalitat de Catalunya.

${ }^{96}$ Art. 122 LCSP en redacción dada por R. Decreto Ley 14/2019.
} 
se deroga la Directiva 95/46/CE, en aquellos contratos cuya ejecución requiera el tratamiento por el contratista de datos personales por cuenta del responsable del tratamiento, adicionalmente en el pliego se hará constar:

a) La finalidad para la cual se cederán dichos datos ${ }^{97}$.

b) La obligación del futuro contratista de someterse en todo caso a la normativa nacional y de la Unión Europea en materia de protección de datos, sin perjuicio de lo establecido en el último párrafo del apartado 1 del art. 202.

c) La obligación de la empresa adjudicataria de presentar antes de la formalización del contrato una declaración en la que ponga de manifiesto dónde van a estar ubicados los servidores y desde dónde se van a prestar los servicios asociados a los mismos ${ }^{98}$.

d) La obligación de comunicar cualquier cambio que se produzca, a lo largo de la vida del contrato, de la información facilitada en la declaración a que se refiere la letra c) anterior.

e) La obligación de los licitadores de indicar en su oferta, si tienen previsto subcontratar los servidores o los servicios asociados a los mismos, el nombre o el perfil empresarial, definido por referencia a las condiciones de solvencia profesional o técnica, de los subcontratistas a los que se vaya a encomendar su realización ${ }^{99}$.

En los pliegos correspondientes a los contratos a que se refiere el párrafo anterior las obligaciones recogidas en las letras a) a e) anteriores en todo caso deberán ser calificadas como esenciales a los efectos de lo previsto en la letra f) del apartado 1 del art. 211.

\subsection{La protección de datos en la documentación a presentar por los licitadores en su oferta}

${ }^{97}$ Por Resolución R/02526/2015, de la Agencia Española de Protección de Datos se impuso una sanción a un Ayuntamiento por publicar datos personales de los trabajadores objeto de subrogación. Así, este Ayuntamiento publicó en su página web un concurso para la contratación de los servicios para Piscinas e Instalaciones dependientes del Instituto Municipal de Deportes. En los Pliegos Técnicos y administrativos publicados se incluyó una lista con los trabajadores a subrogar. Los datos que se publicaron fueron: Nombre y apellidos, D.N.I., antigüedad, categoría y jornada. La Agencia señaló que "El principio de transparencia, como justificación para la difusión de los datos no puede ser tenido en cuenta porque la identidad de los trabajadores asociada a su perfil profesional no resulta de una relevancia pública que justifique su acceso universal mediante su publicación en la web pudiendo resultar suficiente su conocimiento por los licitadores en el trámite de acceso restringido o tras la adjudicación En consecuencia, la denunciada podría haber ofrecido la misma información para dicha finalidad sin necesidad de publicar los datos de los trabajadores de la UTE, no precisándose divulgar indiscriminadamente a través de la web los datos concretos de las personas". Criterio establecido por esta Agencia, entre otros procedimientos en los AP/00020/2010, AP/00029/2011 y AP/00030/2014, referentes a la divulgación en abierto en el Portal del contratante de la identidad de los trabajadores implicados en procedimientos de subrogación.

98 La declaración sobre ubicación de los servidores y desde dónde se van a prestar los servicios asociados a los mismos debe aportarse antes de la formalización del contrato, siendo su presentación imprescindible para que el contrato pueda perfeccionarse (Informe 4/2020 de la Junta Consultiva de Contratación Pública del Estado).

${ }^{99}$ La obligación de los licitadores de indicar en su oferta si tienen previsto subcontratar los servidores o los servicios asociados a los mismos, prevista en el literal e) del art. 122.2 de la Ley 9/2017, de 8 de noviembre, de Contratos del Sector Público, tiene carácter esencial, no siendo subsanable su omisión y debiendo procederse, en caso de inobservancia, a la exclusión del licitador (Informe 4/2020 de la Junta Consultiva de Contratación Pública del Estado). 


\subsubsection{Subcontratación de servidores}

Los licitadores deberán indicar en su oferta si tienen previsto subcontratar los servidores o los servicios asociados a los mismos y el nombre o el perfil empresarial, definido por referencia a las condiciones de solvencia profesional o técnica, de los subcontratistas a los que se vaya a encomendar su realización ${ }^{100}$.

\section{Obligación del adjudicatario}

\subsection{Declaración de la ubicación de servidores}

Será obligación de la empresa adjudicataria presentar antes de la formalización del contrato una declaración en la que ponga de manifiesto dónde van a estar ubicados los servidores y desde dónde se van a prestar los servicios asociados a los mismos ${ }^{101}$. Como señala el Informe 4/2020 de la Junta Consultiva de Contratación Pública del Estado "la obligación de presentar una declaración sobre la localización de los servidores afecta exclusivamente a quien resulte adjudicatario del contrato, no siendo exigible al resto de licitadores". Y añade que "si antes de la formalización del contrato la empresa adjudicataria no aporta la declaración sobre la ubicación de los servidores, se entenderá que el contrato no puede formalizarse por una causa que le es imputable, procediéndose conforme a lo previsto en el apartado 4 del artículo 153 y adjudicándose el contrato al siguiente licitador, por el orden en que hubieran quedado clasificadas las ofertas”.

\subsection{Comunicación de cambios}

Tendrán la obligación de comunicar cualquier cambio que se produzca, a lo largo de la vida del contrato, de la información facilitada en materia de ubicación de ordenadores o subcontratación de servidores.

\section{La protección de datos en el contenido del contrato}

En el texto del contrato se deberá hacer referencia a la legislación aplicable al contrato, con expresa mención al sometimiento a la normativa nacional y de la Unión Europea en materia de protección de datos ${ }^{102}$.

\section{La protección de datos como condición especial de ejecución del contrato. Obligación esencial}

En los pliegos correspondientes a los contratos cuya ejecución implique la cesión de datos por las entidades del sector público al contratista será obligatorio el establecimiento de una condición especial de ejecución que haga referencia a la obligación

100 Art. 122.2.e) LCSP, en redacción dada por R. Decreto-ley 14/2019.

101 Art. 122.2.c) LCSP, en redacción dada por R. Decreto-ley 14/2019.

102 Art. 135.1.d) LCSP, en redacción dada por R. Decreto-ley 14/2019. 
del contratista de someterse a la normativa nacional y de la Unión Europea en materia de protección de datos ${ }^{103}$.

\section{El incumplimiento de la condición especial como causa de resolución}

En los pliegos se advertirá además al contratista de que esta obligación tiene el carácter de obligación contractual esencial de conformidad con lo dispuesto en la letra f) del apartado 1 del art. 211. Es decir, su incumplimiento sería causa de resolución del contrato. Además, la resolución por esta causa conlleva que quedará incursa en prohibición para contratar $^{104}$.

\section{La protección de datos en la subcontratación}

Se establece la obligación del subcontratista a que hace referencia el último párrafo del apartado 1 del art. 202 referida al sometimiento a la normativa nacional y de la Unión Europea en materia de protección de datos ${ }^{105}$.

\section{Causa de nulidad de Derecho Administrativo}

Se incluye como causa de nulidad de derecho administrativo la falta de mención en los pliegos de lo previsto en los párrafos tercero, cuarto y quinto del apartado 2 del art. $122 \operatorname{LCSP}^{106}$.

\section{La protección de datos en el registro de contratos del sector público}

Se hace una referencia a la protección de datos en el Registro de Contratos ${ }^{107}$.

103 Art. 202.1 LCSP, en redacción dada por R. Decreto-ley 14/2019.

104 Art. 5 R. Decreto-ley 14/2019, da nueva redacción a la letra d) del apartado 2 del art. 71 LCSP: “d) Haber dado lugar, por causa de la que hubiesen sido declarados culpables, a la resolución firme de cualquier contrato celebrado con una entidad de las comprendidas en el artículo 3 de la presente Ley. La prohibición alcanzará a las empresas cuyo contrato hubiere quedado resuelto por incumplimiento culpable del contratista de las obligaciones que los pliegos hubieren calificados como esenciales de acuerdo con lo previsto en el artículo 211.1.f)”.

${ }^{105}$ Art. 215.4 LCSP en redacción dada por R. Decreto-ley 14/2019. "Los subcontratistas quedarán obligados solo ante el contratista principal que asumirá, por tanto, la total responsabilidad de la ejecución del contrato frente a la Administración, con arreglo estricto a los pliegos de cláusulas administrativas particulares o documento descriptivo, y a los términos del contrato; incluido el cumplimiento de las obligaciones en materia medioambiental, social o laboral a que se refiere el artículo 201, así como de la obligación a que hace referencia el último párrafo del apartado 1 del artículo 202 referida al sometimiento a la normativa nacional y de la Unión Europea en materia de protección de datos”.

${ }^{106}$ En su redacción dada por el art. 5 R. Decreto-ley 14/2019.

107 Art. 346.5 LCSP: "El Registro de Contratos del Sector Público facilitará de modo telemático el acceso a sus datos a los órganos de las Administraciones Públicas que los precisen para el ejercicio de sus competencias legalmente atribuidas. Asimismo, de conformidad con lo establecido en la Ley 19/2013, de 9 de diciembre, de transparencia, acceso a la información pública y buen gobierno, y con las limitaciones que imponen las normas sobre protección de datos de carácter personal, facilitará el acceso público a los datos que no tengan el carácter de confidenciales y que no hayan sido previamente publicados de modo telemático y a través de Internet”. 


\section{Otras disposiciones en materia de protección de datos de carácter personal}

Existen otras disposiciones sobre esta materia ${ }^{108}$. La LCSP recoge además las siguientes obligaciones:

1. Respeto a la normativa ${ }^{109}$

2. Encargado de tratamiento ${ }^{110}$

3. Caso de que un tercero trate datos personales por cuenta del contratista, encargado del tratamiento ${ }^{111}$.

\section{EL ACCESO A LA INFORMACIÓN DE LA CONTRATACIÓN EN LAS RESOLUCIONES DEL CONSEJO DE TRANSPARENCIA Y BUEN GOBIERNO U ÓRGANOS EQUIVALENTES DE LAS COMUNIDADES AUTÓNOMAS}

La Ley 19/2013 de 9 de diciembre, de transparencia, acceso a la información y buen gobierno (LTAIBG) establece, por primera vez, en nuestro ordenamiento jurídico administrativo, un conjunto articulado de medidas destinadas a garantizar la transparencia de la actividad de nuestras instituciones y Administraciones Públicas. Estas medidas se desenvuelven en dos direcciones: por un lado, establecen una serie de obligaciones positivas para los sujetos comprendidos en su ámbito de aplicación, consistentes en publicar de forma proactiva determinados datos o informaciones relativos a su organización y la actividad que desarrollan; por otro, desarrollan el derecho de la ciudadanía a acceder a la información obrante en los archivos y registros de las organizaciones públicas, establecido en el art. 105 de la Constitución Española (en adelante CE), y garantizan que dichos sujetos habrán de responder y tramitar las solicitudes de acceso de los ciudadanos y ciudadanas de forma adecuada y con las garantías oportunas. El primer grupo de medidas

\footnotetext{
${ }^{108}$ Disp. adicional vigésima quinta LCSP.

109 “Los contratos regulados en la presente Ley que impliquen el tratamiento de datos de carácter personal deberán respetar en su integridad la Ley Orgánica 15/1999, de 13 de diciembre, de Protección de Datos de Carácter Personal y su normativa de desarrollo”.

110 "Para el caso de que la contratación implique el acceso del contratista a datos de carácter personal de cuyo tratamiento sea responsable la entidad contratante, aquel tendrá la consideración de encargado del tratamiento.

En este supuesto, el acceso a esos datos no se considerará comunicación de datos, cuando se cumpla lo previsto en el Art. 12.2 y 3 de la Ley Orgánica 15/1999, de 13 de diciembre. En todo caso, las previsiones del Art. 12.2 de dicha Ley deberán de constar por escrito”.

Obligaciones al finalizar la prestación contractual:

“Cuando finalice la prestación contractual los datos de carácter personal deberán ser destruidos o devueltos a la entidad contratante responsable, o al encargado de tratamiento que esta hubiese designado.

El tercero encargado del tratamiento conservará debidamente bloqueados los datos en tanto pudieran derivarse responsabilidades de su relación con la entidad responsable del tratamiento”.

${ }^{111}$ En este caso deberán de cumplirse los siguientes requisitos:

a) Que dicho tratamiento se haya especificado en el contrato firmado por la entidad contratante y el contratista.

b) Que el tratamiento de datos de carácter personal se ajuste a las instrucciones del responsable del tratamiento.

c) Que el contratista encargado del tratamiento y el tercero formalicen el contrato en los términos previstos en el art. 12.2 de la Ley Orgánica 15/1999, de 13 de diciembre.

En estos casos, el tercero tendrá también la consideración de encargado del tratamiento.
} 
es denominado en la Ley “publicidad activa” y está regulado principalmente en el Capítulo II, así denominado, del Título I, “Transparencia de la actividad pública”; el segundo es denominado “derecho de acceso a la información pública” y aparece regulado en el Capítulo III, también así denominado, del mismo Título ${ }^{112}$. El art. 8 LTAIBG, incardinado en el apartado de publicidad activa, señala la obligación de hacer pública, través de alguno de los medios previstos en el art. 5.1, cierta información de contratos ${ }^{113}$. Por otra parte, de acuerdo con lo previsto en el art. 12 LTAIBG "todas las personas tienen derecho a acceder a la información pública, en los términos previstos en el artículo 105.b) de la Constitución Española, desarrollados por esta Ley”.

Cada vez más los ciudadanos requieren más información sobre determinados contratos públicos, sin necesidad de ser licitadores o haber participado en la licitación, y ante la negativa o silencio de la Administración se ha configurado en la normativa de transparencia citada la posibilidad de recurrir ante el Consejo de Transparencia y Buen Gobierno u órganos equivalentes de las Comunidades Autónomas. Es decir, además de la vía de recurso especial en materia de contratación (en los supuestos, requisitos y trámites establecidos en los arts. 44 a 60 LCSP) o recurso administrativo o jurisdiccional de que disponen los licitadores, se abre una vía encaminada a obtener información por los ciudadanos que igualmente puede ser utilizada en materia de contratación (el derecho de acceso a la información pública), presentando la reclamación correspondiente ${ }^{114}$. La Sentencia ${ }^{\circ} 46 / 2017$, de 22 de junio, del Juzgado Central de lo Contencioso-Administrativo $\mathrm{n}^{\circ} 2$ de Madrid, ha destacado que "el derecho de acceso a la información es un derecho fundamental reconocido a nivel internacional como tal, debido a la naturaleza representativa de los gobiernos democráticos; es un derecho esencial para promover la transparencia de las instituciones públicas y para fomentar la participación ciudadana en la toma de decisiones. Además, las Administraciones Públicas se financian con fondos procedentes de los contribuyentes y su misión principal consiste en servir a los ciudadanos por lo que toda la información que generan y poseen pertenece a la ciudadanía”.

De igual modo deben tenerse en cuanta la existencia de determinados límites en el acceso a la información, que se recogen en los arts. 14 y 15 LTAIBG. A continuación, sin ánimo de exhaustividad por razones de espacio, vamos a exponer brevemente una selección de referencias a resoluciones del Consejo de Transparencia y Buen Gobierno y órganos similares de las Comunidades Autónomas, con carácter sistemático para establecer una tipología de supuestos, sobre diversas cuestiones relacionadas con el acceso a información

112 Criterio interpretativo 2/2019 CTBG.

113 “a) Todos los contratos, con indicación del objeto, duración, el importe de licitación y de adjudicación, el procedimiento utilizado para su celebración, los instrumentos a través de los que, en su caso, se ha publicitado, el número de licitadores participantes en el procedimiento y la identidad del adjudicatario, así como las modificaciones del contrato. Igualmente serán objeto de publicación las decisiones de desistimiento y renuncia de los contratos. La publicación de la información relativa a los contratos menores podrá realizarse trimestralmente. Asimismo, se publicarán datos estadísticos sobre el porcentaje en volumen presupuestario de contratos adjudicados a través de cada uno de los procedimientos previstos en la legislación de contratos del sector público".

${ }^{114}$ Art. 24. LTAIBG. Reclamación ante el Consejo de Transparencia y Buen Gobierno: “1. Frente a toda resolución expresa o presunta en materia de acceso podrá interponerse una reclamación ante el Consejo de Transparencia y Buen Gobierno, con carácter potestativo y previo a su impugnación en vía contenciosoadministrativa”. 
de la contratación pública, en las que ciudadanos acuden a estos órganos en petición de acceso a determinada información de contratos que no le ha sido facilitada o denegada. Para facilitar su análisis hemos establecido una tipología de las mismas, aunque en algunos casos una misma resolución puede recoger varios supuestos:

\section{Contratos menores: datos o relaciones}

Si bien la LTAIBG establece esta obligación de publicar los contratos menores (art. 8), son muchas las resoluciones estimando las reclamaciones de acceso a estos datos $^{115}$. En este sentido, la R.T. 0273/2016, de 31 de enero de 2017. A su vez, la Resolución 126/2019, de 23 de abril del Consejo de Transparencia y Protección de Datos de Andalucía estima parcialmente la solicitud.

\section{Acceso a pliegos}

Es significativa la R.0084/2016 de 6 de junio de 2016, del Consejo de Transparencia y Buen Gobierno (CTBG) relativa a acceso pliegos de suministro de trenes de alta velocidad.

\section{Copia del contrato}

El CTBG estima la reclamación de facilitar el acceso al contrato suscrito entre el Ministerio de Justicia y un despacho de abogados para la defensa de un magistrado en Bélgica (R.0569/2018, de 20 diciembre de 2018). También estima la reclamación de acceso al contrato de la DG Policía y Guardia Civil para líneas telefónicas fijas y terminales (R.0260/2018, de 23 julio 2018). De igual modo dispone el acceso a los contratos del Ministerio de Defensa con Imprentas (R.0656/2018, de 27 diciembre 2018). Es de reseñar la R.0022/2018, de 9 de abril de 2018, que fue objeto de impugnación en vía jurisdiccional relativa al acceso a la copia del contrato con la Corporación RTVE del programa "como lo ves”, resuelto por sentencia 3/2019 del Juzgado Central contencioso-administrativo de fecha 25 enero 2019. De igual modo, la R.0520/2018 estimó el acceso a la copia de un contrato adjudicado a una productora de TV ${ }^{116}$.

4. Solicitud de identificación de empresas a las que se solicitó presupuesto

Es interesante la R.T 0386/2018 de 24 de enero de 2019, relativa al acceso a copia de contrato e identificación de las cinco empresas a las que se solicitó presupuesto.

5. Solicitud de número de efectivos de un contrato

\footnotetext{
115 Consejo de trasparencia: RT 0567/2019, de 15 de noviembre de 2019; R.0029/2019, de 9 de abril de 2019; R.0394/2018, de 1 de octubre de 2018; RT 0057/2016, de 20 de junio de 2016; RT 0273/2016, de 31 de enero de 2017.

116 Vid. RSCTG 073/2018, de 19 de septiembre; RSCTG.053/2018, de 27 de junio y RSCTG 040/2018, de 27 de junio de 2018.
} 
La R.0203/2016, de 26 de julio de 2016 estima la reclamación de acceso al número de efectivos del personal de limpieza adscrito al contrato de limpieza de dependencias de establecimientos penitenciarios.

6. Contratos públicos otorgados a una determinada persona

Por R.T. 0482/208 de 13 de febrero de 2019, se estima la solicitud de acceso ${ }^{117}$. La Resolución 32/2019, de 12 de febrero, del Consejo de Transparencia y Protección de Datos de Andalucía, se estima parcialmente y la Resolución 11/2018, de 17 de enero, del Consejo de Transparencia y Protección de Datos de Andalucía, sobre contratos adjudicados a determinada persona, se pronuncia en igual sentido.

7. Expedientes de obra: cómo se construyó una carretera

La R.T 0065/2016, de 23 junio de 2016, estima parcialmente la solicitud. También hay resoluciones sobre acceso a información de obras.

8. Obras y Coste final de obras

Cabe mencionar la R.0231/2016, de 27 de agosto de 2016; la Resolución 156/2018, de 17 de agosto, de la Comisión de Transparencia de Castilla-León relativa a solicitud de documentación de obras de soterramiento de cableado y AR 9/2017, de 28 de agosto de 2017, del Consejo de Transparencia de Navarra sobre acceso a información concerniente a obras de arreglo de varias calles.

9. Memoria justificativa de la necesidad del contrato y justificación de procedimiento negociado

Se estima la solicitud por R.0739/2018, de 5 de marzo de $2018^{118}$.

\section{Acceso al expediente completo}

Destacan la R. 0709/2018, de 21 de febrero de 2019, relativa al acceso a licitación completa del contrato de transporte de personal de Renfe ${ }^{119}$ y la 246/2019, de 9 de agosto del Consejo de Transparencia y Protección de Datos de Andalucía (acceso a contratos de suministro de flores, plantas y material de jardinería, años 2017 y 2018).

11. Expedientes de adjudicación de contratos. Informes de valoración

117 Vid. R.T. 0136/2019, de 16 de abril. También R.T.0056/2019, de 29 de abril de 2019.

118 De igual modo, la R.T.0783/2019, de 11 de marzo. Vid. también la R. 0542/2018, de 12 de diciembre.

119 Y la Sentencia 125/2019 del Juzgado Central Contencioso administrativo de fecha 25 noviembre de 2019. Sobre este tema de acceso al expediente completo, relativo al suministro de equipos informáticos y de equipos multifuncionales e impresoras se pronuncia la R.0214/2016 de 12 de enero de 2017. Vid. también la RSCTG 45/2017, de 9 de octubre de 2017. 
La R.0569/2019, de 25 de noviembre de 2019, estima la reclamación relativa al acceso al expediente de adjudicación de defensa jurídica y representación en juicio ${ }^{120}$.

\section{Situación de contratos}

La R.T. 02-48/2016 de 16 febrero de 2017, estima reclamación de situación de contratos actuales de televisión y telefonía en habitaciones de cada uno de los hospitales de la Comunidad de Madrid.

\section{Relación de películas adquiridas}

Por R.0534/2017, de 22 de enero de 2018, se accede a la reclamación de la relación de películas de cine adquiridas a determinada empresa.

\section{Documento de suspensión de contrato}

Por R.T.0326/2018, de 29 de diciembre de 2018, se estima la reclamación de acceso a esta información.

\section{Número de contratos adjudicados}

Es frecuente que se solicite acceso al número de contratos adjudicados en un determinado periodo de tiempo a determinadas entidades mercantiles. En ese sentido, cabe mencionar la R. 125/2019, de 22 de mayo.

16. Presentación de reclamación cuando aún existía la posibilidad de formular recurso especial en materia de contratación

En virtud de la R.0282/2018, de 7 de agosto de 2018. se desestima, en base a la Disposición Adicional Primera, apartado 1, de la LTAIBG ${ }^{121}$.

${ }^{120}$ Vid. también la Comissió de Garantía del Dret d’accés a la Informació Publica, Resolución 21/2017, de 1 de febrero:

Administración reclamada: Servicio Catalán de la Salud.

Información reclamada: Acceso por un licitador a determinados documentos integrantes del expediente de contratación (el informe técnico de valoración y documentación presentada por otros tres licitadores relativa a sus ofertas técnicas) antes de su adjudicación.

Sentido de la resolución: Estimación parcial.

"Los licitadores tienen derecho a acceder al expediente de contratación antes de que se produzca la adjudicación del contrato. Las empresas que participan en una licitación pueden exigir que algunos de los datos que aportan no sean facilitados a la ciudadanía y a los competidores, o que lo sean solo con determinadas garantías. La declaración de confidencialidad de los licitadores no vincula al órgano de contratación, que es quien debe terminar decidiendo, de forma motivada, si la información en cuestión merece o no ser protegida y ser mantenida confidencial, en función de su contenido. La declaración de confidencialidad que puedan hacer los licitadores no puede abarcar la totalidad de la documentación presentada ni tener una motivación genérica, sino que debe indicar con precisión los concretos documentos afectados y las razones objetivas y específicas que justifican su confidencialidad”.

${ }^{121}$ Porque el acceso a la documentación solicitada debe resolverse en vía de recurso especial, por el órgano de contratación competente para su resolución, no por el Consejo de Transparencia. 


\section{Modificaciones de contrato}

Por R.0035/2017, de 21 de abril de 2017, del Consejo de Transparencia se concedió el acceso. Esta Resolución fue recurrida por el Ministerio de Fomento y desestimada por la Sentencia $n^{0} 15 / 2018$, de 24 de febrero, del Juzgado Central Contencioso-Administrativo $\mathrm{n}^{\circ} 1$, reconociendo el derecho a acceder a esta información.

18. Acceso a facturas

Por R.0245/2018, de 17 de julio de 2018. se estimó parcialmente la reclamación de acceso.

19. Acceso a contratos publicitarios

Destacan la R. 0039/2019, de 17 de abril de 2019; la Resolución 100/2017, de 15 de septiembre (Comisión de Transparencia de Castilla y León) y la RSCTG 0085/2017, de 20 de diciembre de 2017.

20. Acceso a contratos de televisión

En este sentido cabe hacer referencia a la R.0617/2019, de 22 de noviembre de 2019 y a la R.0607/2019, de 22 de noviembre de 2019.

21. Contratos de protocolo (datos de almuerzos, copas de vino)

Merece destacarse la R.T. 0485/2019, de 24 de octubre de 2019, sobre acceso a datos de comidas institucionales, vinos y otros actos protocolarios.

22. Copia de documentación acreditativa de incumplimientos de contrato

Por R.T.0191/2017, de 4 de diciembre de 2017, ratificada por Sentencia $\mathrm{n}^{0} 107 / 2018$, de 7 de septiembre, del Juzgado Central Contencioso-Administrativo $\mathrm{n}^{0} 10$, se desestima el acceso porque no pueden constar datos personales de los trabajadores.

23. Importe de indemnizaciones abonadas por desistimiento de contrato

En este tema cabe citar la Resolución 8/2018 de 4 de junio de la Comisión Vasca de Acceso a la Información Pública.

24. Contratos de espectáculos

Sobre esta cuestión destaca la R.T.0399/2018, de 25 de enero de 2018.

25. Acceso a información sobre pruebas deportivas

Merecen reseñarse el Informe 1/2018 de 23 de julio del Consejo de Transparencia de Aragón (prueba motociclista) y la Resolución 26/2019 de 8 de febrero, del Consejo de 
Transparencia y Protección de Datos de Andalucía sobre información detallada de todos los costes e ingresos de una carrera popular.

26. Informe por el cual se escogió a la empresa seleccionada

Cabe traer a colación al respecto la RSCTG 24/2020, de 29 de abril de 2020.

27. Contratos relativos a centros de menores, centros de internamiento y/o de acogida de menores

Sobre este tema cabe aludir al Acuerdo AR 06/2020, de 2 de marzo, del Consejo de Transparencia de Navarra.

28. Copia del acta de la Mesa de contratación

La Resolución 81/2019 de 4 de diciembre, de la Comisión Vasca de Acceso a la Información Pública estima la solicitud de acceso a las actas de la Mesa que no habían sido publicadas en el Perfil del contratante, tal y como establece el art. 63.3 de la LCSP.

\section{CONCLUSIONES}

$1^{\text {a) }}$ El secreto de la presentación de ofertas garantiza la igualdad de todos los licitadores.

$2^{a}$ ) Debe mantenerse el secreto de la oferta en el supuesto de que se valoren criterios mediante juicios de valor y criterios mediante fórmulas, de tal modo que no se introduzca información del segundo en el primero.

$3^{\mathrm{a}}$ ) El secreto en el anuncio de la formalización de los contratos debe ceñirse con carácter restrictivo a los supuestos del art.154 de la LCSP.

$4^{a}$ ) Se deben potenciar los concursos con intervención de jurado mediante presentación anónima.

$\left.5^{a}\right)$ El secreto abarca también la obligación de no comunicar entre licitadores sus ofertas durante el plazo de convocatoria y presentación de ofertas y el respeto a la normativa de competencia.

$\left.6^{a}\right)$ La transparencia es esencial en todas las fases de la contratación pública, desde la fase preparatoria del contrato a través de las consultas preliminares de mercado y en la fase de licitación a través de la publicidad de la licitación y de los pliegos y demás documentos, así como la información a los licitadores de las consultas que formulen. En la fase de adjudicación, en cuanto a la motivación de la adjudicación, su notificación y publicación, en el acceso a la documentación de los demás licitadores, así como a la valoración efectuada por los órganos correspondientes de la Administración. Por último, en la fase de ejecución por lo que respecta a las modificaciones de los contratos, prórrogas, etc. 


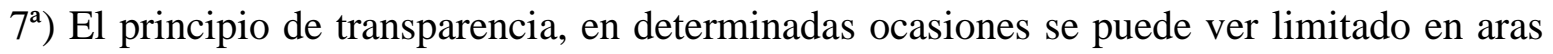
al principio de confidencialidad para garantizar que determinada información del licitador que presenta su oferta incluyendo secretos técnicos o comerciales o que afecten a la competencia, pueda llegar al resto de los licitadores, y de este modo puedan tener acceso a una información que debe estar protegida y que podría ser utilizada por los mismos frente al titular de esos secretos comerciales.

$8^{a}$ ) En el conflicto entre el derecho de defensa de un licitador descartado, y el derecho de protección de los intereses comerciales del licitador adjudicatario, se ha de buscar el equilibrio adecuado, de forma que ninguno de ellos se vea perjudicado más allá de lo necesario.

9a) La confidencialidad no puede tener carácter absoluto y no puede abarcar la totalidad de la oferta.

$10^{\mathrm{a}}$ ) La confidencialidad debe venir referida a secretos técnicos o comerciales o que comporten una ventaja competitiva o que se trate de una información verdaderamente reservada y que represente un valor estratégico para la empresa y que pueda afectar a su competencia en el mercado.

11ª El deber de confidencialidad no podrá impedir la divulgación de partes no confidenciales de los contratos.

12a) La protección de datos personales en la contratación pública ha sido reforzada mediante el Real Decreto-ley 14/2019, de 31 de octubre y abarca todas las fases de la contratación desde la preparación del contrato a través de determinada información que deben contener los pliegos, en la fase de presentación de ofertas como es la indicación de subcontratación de servidores y en la fase de adjudicación respecto a la declaración de ubicación de servidores, así como en la fase de ejecución mediante la inclusión de determinados datos en las condiciones especiales de ejecución, causa de resolución en la subcontratación y causa de nulidad.

$13^{a}$ ) Con el acceso a la información a través de la normativa de transparencia se abre una vía encaminada a obtener información por los ciudadanos, que igualmente puede ser utilizada en materia de contratación, presentando la reclamación correspondiente y que ha dado lugar a numerosas resoluciones del Consejo de Transparencia y Buen Gobierno y órganos similares de las CCAA.

\section{BIBLIOGRAFÍA CITADA}

- BASSOLS COMA, M., "La confidencialidad en la resolución del recurso especial en materia de contratación en el sector de la defensa y la seguridad pública y el Tribunal Administrativo Central de Recursos Contractuales”, Documentación Administrativa, N ${ }^{\circ}$ 288, 2010. 
- GARCÍA PÉREZ. M, “El régimen jurídico de las normas y actos administrativos”, en MEILÁN GIL, J.L. y GARCÍA PÉREZ, M., Norma y actos administrativos, Iustel, $1^{\text {a }}$ edición, 2018

- MORENO MOLINA, J.A., Los principios generales de la contratación de las Administraciones Públicas, editorial Bomarzo, 2006.

- VILLAR PALASÍ, J.L., Lecciones sobre contratación administrativa, Facultad de Derecho, Sección de publicaciones, 1969. 